\title{
Esporogénesis, esporodermo y ornamentación de esporas maduras en Lycopodiaceae
}

\author{
Edgar Javier Rincón Baron ${ }^{1,2}$, Cristina Hilda Rolleri³ ${ }^{3}$ Lilian M. Passarelli³, \\ Silvia Espinosa Matías ${ }^{4} \&$ Alba Marina Torres G. ${ }^{2}$
}

1. Grupo de Estudios Botánicos y Docente del Instituto de Biología, Universidad de Antioquia, calle 67 N 53 -108, Medellín, Colombia; ejrbaron@gmail.com

2. Grupo Ecología y Diversidad Vegetal, Departamento de Biología, Calle 13 No 100-00, Universidad del Valle, Sede Meléndez, Cali, Colombia; alba.torres@correounivalle.edu.co

3. Laboratorio de Estudios de Anatomía Vegetal Evolutiva y Sistemática (LEAVES), Facultad de Ciencias Naturales y Museo, Universidad Nacional de La Plata, 64 No 3 e/119 y 120 La Plata B1904 DZB, Buenos Aires, Argentina; tinar.cris@gmail.com,1mpassarelli@yahoo.com.ar

4. Laboratorio de Microscopía Electrónica de Barrido, Facultad de Ciencias, Universidad Nacional Autónoma de México, Av. Universidad 3000, C.P. 04510, México, D.F., México; sem@unam.mx

Recibido 08-XI-2013. Corregido 20-II-2014. Aceptado 26-III-2014.

\begin{abstract}
Sporogenesis, sporoderm and mature spore ornamentation in Lycopodiaceae. Studies on reproductive aspects, spore morphology and ultrastructure of Lycopodiaceae are not very common in the scientific literature, and constitute essential information to support taxonomic and systematic relationships among the group. In order to complete existing information, adding new and broader contributions on these topics, a comparative analysis of the sporogenesis ultrastructure, with emphasis on cytological aspects of the sporocyte coat development, tapetum, monoplastidic and polyplastidic meiosis, sporoderm ontogeny and ornamentation of the mature spores, was carried out in 43 taxa of eight genera of the Lycopodiaceae: Austrolycopodium, Diphasium, Diphasiastrum, Huperzia (including Phlegmariurus), Lycopodium, Lycopodiella, Palhinhaea and Pseudolycopodiella growing in the Andes of Colombia and the Neotropics. For this study, the transmission electron microscopy (TEM) samples were collected in Cauca and Valle del Cauca Departments, while most of the spores for scanning electron microscopy (SEM) analysis were obtained from herbarium samples. We followed standard preparation procedures for spore observation by TEM and SEM. Results showed that the sporocyte coat is largely composed by primary wall components; the sporocyte develop much of their metabolic activity in the production of their coat, which is retained until the spores release; protective functions for the diploid cells undergoing meiosis is postulated here for this layer. The abundance of dictyosomes in the sporocyte cytoplasm was related to the formation and development of the sporocyte coat. Besides microtubule activity, the membrane of sporocyte folds, associated with electrodense material, and would early determine the final patterns of spore ornamentation. Monoplastidic condition is common in Lycopodium s.l., whereas polyplastidic condition was observed in species of Huperzia and Lycopodiella s. l.. In monoplastidic species, the tapetum presents abundant multivesicular bodies, while in polyplastidic species, the secretory activity of the tapetum is less intense. Sporoderm development is centripetal, exospore is the first formed layer, then the endospore and, if present, perispore is the final deposited layer. Adult spores of the Lycopodiaceae showed two patterns of ornamentation: negative or caviform (foveolate spores) and positive or muriform ornamentation, the latter with two subtypes (rugate and reticulate spores). The spores of Huperzia are characteristically foveolate, the rugate spores were found in a few species of Huperzia and in all of the Lycopodiella s. l. taxa studied, while Lycopodium s.l. spores bear reticulate ornamentation. Numerous ornamentation traits are diagnostic at the specific level. The types of ornamentation found do not support the recent extreme fragmentation of the family in several genera, but could match, a priori, with the idea of three subfamilies. The findings of sporogenesis, extremely similar in all taxa studied, point more to consider fewer genera, more comprehensive, than the recent, marked splitting of the family. Rev. Biol. Trop. 62 (3): 1161-1195. Epub 2014 September 01.
\end{abstract}

Key words: Lycopodiaceae, sporangium ontogeny, sporoderm, sporogenesis, spore ornamentation, ultrastructure. 
Los licófitos representan un grupo antiguo de plantas vasculares que tuvieron su origen en el Silúrico, hace unos 420 millones de años, cuando se habría separado de las demás plantas vasculares (Raubeson \& Jansen, 1992). En su historia evolutiva hubo numerosas extinciones y actualmente los licófitos incluyen a las Isoetales, del Devónico ( 380 millones de años), las Selaginelales y las Licopodiales del Carbonífero ( $\sim 300-360$ millones de años), época en que fueron especialmente abundantes, diversos y representaron casi el $50 \%$ de la flora global (DiMichele \& Skog, 1992; Willis \& McElwain, 2002; Ambrose, 2013). Tienen numerosos representantes fósiles hasta el Cretácico (hace 140 75 millones de años), periodo en que experimentan una brusca disminución que coincide con la diversificación de las Angiospermas. Schneider et al. (2004) sugieren que la diversificación del grupo después del Cretácico es un caso de oportunismo ecológico, en un escenario evolutivo posterior a la diversificación de las plantas con flores. Wikström, Kenrick \& Chase (1999) señalan que hace unos 15 millones de años, como consecuencia de procesos orogénicos en páramos de los Andes, los licófitos habrían adquirido un hábito epifítico y posteriormente experimentaron una reversión a la condición terrestre, especialmente los táxones de Huperzia Bernh. En la actualidad representan el grupo más antiguo de plantas vasculares con unas 1300 especies (Ambrose, 2013). Comparten con las angiospermas más del $90 \%$ del genoma que regula el desarrollo del cuerpo vegetal, lo que ha llevado a utilizarlos como grupo estratégico para el entendimiento de procesos evolutivos y moleculares. Se les considera monofiléticos (Smith, Pryer, Schuettpelz, Korall, \& Schneider, 2006), los licófitos son diferentes de los helechos o monilófitos por la presencia de microfilos en lugar de megafilos (eufilos), de espermatozoides biflagelados y no pluriflagelados (Renzaglia, Duff, Nickrent \& Garbary, 2000), además de la ausencia de una inversión génica de 30 Kilobases en una región del genoma del cloroplasto, caracteres que si están presentes en los helechos y los espermatófitos. Los licófitos presentan una inversión en el orden de algunos genes en el ADN de los cloroplastos, que resulta similar al que se halla en briófitos (Kenrick \& Crane, 1997; Wikström \& Kenrick, 1997, 2001; Yatsentyuk, Valiejo, Samigullin, Wikström, \& Troitsky, 2001).

Las Lycopodiaceae P. Beauv. ex Mirb. son cosmopolitas con unas 450 especies que crecen desde el nivel del mar hasta más de $4000 \mathrm{~m}$ de altitud. Arana \& Øllgaard (2012) reportaron 190 especies para Sudamérica, mientras que para Colombia, Murillo, Murillo, León \& Triana (2008) reconocen 78 especies distribuidas en todo el país con excepción de la Orinoquía. La familia fue subdividida por Wagner \& Beitel $(1992,1993)$ en tres subfamilias: Huperzioideae, Lycopodielloideae y Lycopodioideae Wagner \& Beitel. Øllgaard (2012a, b), basándose en las propuestas de Holub (1964, 1975, 1983, 1985, 1991), Wagner \& Beitel $(1992,1993)$ y estudios moleculares de Wikström \& Kenrick (2000 a, b, 2001), aceptó las tres subfamilias y la existencia de 16 géneros, de los cuales nueve citó para el Nuevo Mundo: Huperzia, Phlegmariurus (Herter) Holub (Huperzioideae), Lycopodiella Holub, Pseudolycopodiella Holub y Palhinhaea Franco \& Vasc. (Lycopodielloideae), Austrolycopodium Holub, Diphasiastrum Holub, Diphasium C. Presl ex Rothm. y Lycopodium L (Lycopodioideae), pero no consideró a Dendrolycopodium A. Haines ni a Spinulum A. Haines (Haines, 2003).

En estudios previos sobre Lycopodiaceae resaltan revisiones taxonómicas, sistemáticas y floras locales, como las de Øllgaard (1987, 1988, 1990, 1992, 1996), Santa (1989), Rolleri (1975, 1978, 1981, 1984, 1985 a, b), Rolleri \& Deferrari (1986), Tryon \& Stolze (1994), Murillo \& Harker (1990), Murillo \& Murillo (1999), Rodríguez (2002) y Ramírez \& Macías (2007), trabajos morfológicos, como los de Rolleri (1972 a, b), Rolleri (1979, 1980), Øllgaard (1975) y sobre aspectos citológicos, Rolleri (1982 a, b).

Las investigaciones que tratan aspectos de la biología reproductiva y los procesos de esporogénesis son escasos (Sersic, 1983; Rincón, 
Gélvez, Forero, Arrieta, \& Hleap, 2009). La ontogenia del esporodermo, aspectos de la ultraestructura de los esporocitos, tétradas y esporas maduras fueron estudiados por primera vez con microscopía electrónica de transmisión (MET) por Uehara \& Kurita (1991) en material asiático de Lycopodium clavatum L.

En relación con las esporas, Knox (1950) realizó una prospección de 33 especies de Huperzia y otras especies, agrupadas sub Lycopodium, mientras que Wilce (1972) estudió con microscopía electrónica de barrido (MEB) esporas de 161 especies y estableció tres grandes grupos de acuerdo con la ornamentación, con tipos esporales foveolado-fosulados, rugulados y reticulados, cada uno con subgrupos que llevan el nombre de una especie representativa. Esa autora analizó especies previamente incluidas por Herter (1950) en Lycopodium s. str., y 48 especies de Huperzia (antes reunidos sub Urostachys Herter). Tryon \& Tryon (1982) ilustraron esporas de 12 especies de los géneros actualmente reconocidos, todas sub Lycopodium y, posteriormente, Tryon \& Lugardon (1991) examinaron con MEB 60 especies de Huperzia, 22 de Lycopodium, diez de Lycopodiella y una de Phylloglossum Kunze, y con MET especies como Huperzia selago (L.) Bernh. ex Schrank \& Mart., H. phlegmaria (L.) Rothm., Lycopodiella alopecuroides (L.) Cranfill, L. contexta (Mart.) Holub, L. cernua (L.) Holub, L. lateralis (R. Br.) Øllgaard y Phylloglossum drummondii Kunze. Los trabajos más recientes incluyen los de Solé de Porta \& Murillo-Pulido (2005), Contreras, Bogotá \& Jiménez (2006), Pita, De Menezes \& Prado (2006), Kongoi, Go, Pungga \& Kader (2007), Rolleri, Martínez \& Prada (2010) y Devi \& Singh (2011).

En este estudio se analizaron 43 táxones seleccionados de ocho géneros de Lycopodiaceae: Austrolycopodium, Diphasium, Diphasiastrum, Huperzia (incluyendo Phlegmariurus), Lycopodium, Lycopodiella, Palhinhaea y Pseudolycopodiella. Este trabajo tiene por objetivo hacer un aporte actualizado sobre la mayor parte de los táxones que crecen en Colombia, pero incluyen numerosas especies que también se encuentran distribuidas en otras áreas del Neotrópico. Se analizó y comparó la ultraestructura de los esporocitos, tétradas y esporas de cuatro especies representativas de los géneros Huperzia, Lycopodiella s.l., y Lycopodium s.l. con énfasis en la ontogenia del esporodermo, meiosis monoplastidiales y poliplastidiales y caracteres del tapete. Se discuten las implicaciones sistemáticas y taxonómicas de la ornamentación de las esporas y el valor diagnóstico de este carácter en relación con la subdivisión genérica de la familia.

\section{MATERIALES Y MÉTODOS}

Los 43 táxones de Lycopodiaceae incluidos en este trabajo incluyen una especie de cada uno de los siguientes géneros: Austrolycopodium, Diphasium, Diphasiastrum, Lycopodiella y Pseudolycopodiella, dos subespecies de Lycopodium, seis especies de Palhinhaea y 31 de Huperzia.

La ontogenia del esporodermo se analizó en $H$. brevifolia (Grev. \& Hook.) Holub, $H$. tetragona (Hook. \& Grev.) Trevis., Diphasiastrum thyoides (Humb. \& Bonpl. ex Willd.) Holub y Palhinhaea cernua Franco \& Vasc.

Para la morfología de las esporas maduras, se examinaron con MEB 31 táxones de Huperzia: H. arcuata B. Øllg., H. attenuata (Spring) Trevis., H. brevifolia, H. brongniartii (Spring) Trevis., H. callitrichifolia (Mett.) Holub, H. capellae (Herter) Holub, H. crassa (Humb. \& Bonpld. ex Willd.) Rothm., H. curvifolia (Kunze) Holub, H. dichaeoides (Maxon) Holub, H. dichotoma (Jacq.) Trevis., H. ericifolia (C. Presl) Holub, H. eversa (Poir.) B. Øllgaard, H. firma (Mett.) Holub, H. hartwegiana (Spring) Trevis, H. heteroclita (Desv. ex Poir.) Holub, H. hippuridea (H. Christ) Holub, H. hohenackeri (Herter) Holub, H. hystrix (Herter) Holub, H. kuesteri (Nessel) B. Øllg., $H$. linifolia (L.) Trevis., H. molongensis (Herter) Holub, H. phylicifolia (Desv. ex Poir.) Holub, $H$. reflexa (Lam.) Trevis., H. rosenstockiana (Herter) Holub, H. sarmentosa (Spring) Trevis, H. sellifolia B. Øllg., H. subulata (Desv. ex Poir.) Holub, H. taxifolia (Sw.) Trevis., $H$. 
tenuis (Humb. \& Bonpl. ex Willd.) Trevis., H. tetragona y $H$. unguiculata B. Øllg.; seis de Palhinhaea: P. cernua, P. glaucescens (C. Presl) Holub., P. pendulina (Hook.) Holub., $P$. riofrioi (Sodiro) Holub., P. steyermarkii (B. Øllg.) Holub., P. trianae (Hieron.) Holub; dos subespecies de Lycopodium: L. clavatum subsp. clavatum L, L. clavatum subsp. contiguum (Klotzsch) B. Øllg., y además, Austrolycopodium magellanicum (P. Beauv.) Holub, Diphasium jussiaei (Desv. ex Poir.) Rothm., D. thyoides, Lycopodiella andicola B. Øllg. y Pseudolycopodiella caroliniana (L.) Holub.

Una parte del material utilizado en este estudio fue recolectado por el primer autor en viajes de campo a los departamentos de Caldas, Cauca y Valle del Cauca, y otra parte, proviene de los herbarios de la Universidad del Valle, Cali (CUVC) y de la Universidad del Cauca, Popayán (CAUP). Los especímenes se determinaron con bibliografía reciente sobre el grupo (Øllgaard, 1987, 1988, 1992, 2012 a, 2012 b; Arana \& Øllgaard 2012) y mediante consulta de tipos. Todo el material estudiado se presenta en una lista anexa de especímenes investigados (Apéndice).

Para las observaciones de las muestras con MET 30 esporangios en diferentes etapas de maduración, de cada una de las especies seleccionadas, se fijaron en glutaraldehído al $2.5 \%$ en buffer fosfato, $\mathrm{pH} 7.2$ y $0.2 \mathrm{M}$ por $48 \mathrm{hr}$. Se lavaron en el mismo buffer y se postfijaron adicionalmente con tetróxido de osmio al $2 \%$ por $4 \mathrm{hr}$ a $6^{\circ} \mathrm{C}$ en la oscuridad y con agitación. Las muestras se lavaron con agua destilada, se deshidrataron a $6^{\circ} \mathrm{C}$ durante una hora en cada etapa de la serie de etanol $(30,40,50,60,70$, $80,90,96 \%$ ) y durante $12 \mathrm{hr}$ en etanol $100 \%$. Se embebieron en etanol-resina LR White (London Resin ${ }^{\circledR}, \mathrm{UK}$ ), a $6^{\circ} \mathrm{C}$, efectuándose diez cambios de resina pura durante 12 días, en constante agitación. La inclusión se hizo en resina polimerizada a $60^{\circ} \mathrm{C}$ por $24 \mathrm{hr}$. Las secciones ultrafinas de $70-80 \mathrm{~nm}$ se obtuvieron con cuchilla de diamante y se contrastaron con acetato de uranilo (40min) y citrato de plomo durante $(5 \mathrm{~min}$.). Se observaron con un microscopio JEOL JEM-1011. Para descripciones adicionales, secciones de $0.5 \mu \mathrm{m}$ obtenidas con cuchillas de vidrio se tiñeron con azul de toluidina (TBO) al 1\%, pH 3.4 durante 30 segundos, y fueron observadas en con microscopio fotónico Nikon 80 i eclipse ${ }^{\circledR}$.

Para las observaciones con MEB, de cada uno de los 43 táxones analizados se tomaron tres estróbilos y de estos, se obtuvieron de cinco a diez esporangios maduros según la disponibilidad del material. Los esporangios se colocaron en tubos de material plástico conteniendo etanol $70 \%$ durante $12 \mathrm{hr}$, con el fin de producir la ruptura de la pared y extraer las esporas. La suspensión se pasó a través de un tamiz de $90 \mu \mathrm{m}$ de poro y se transfirió mediante micropipeta a un tubo limpio y cerrado, para llevarla a un baño ultrasónico $(50-60 \mathrm{~Hz}, 90 \mathrm{~W})$ durante $10 \mathrm{~min}$. Luego de este procedimiento, el material fue centrifugado a $5000 \mathrm{rpm} / 5 \mathrm{~min}$, se decantó el sobrenadante y al remanente se le agregó etanol al $70 \%$ para someterlo a otro ciclo de ultrasonido y dos ciclos adicionales de centrifugación con nueva suspensión en etanol. Una gota de la suspensión final se depositó sobre portamuestras cubiertos con cinta conductiva de carbono de doble cara, que se mantuvieron entre dos y $24 \mathrm{hr}$ en desecador plástico utilizando gel de sílice como agente desecante. Luego, las muestras fueron recubiertas con oro en un ionizador JSM-6940, 15v durante $5 \mathrm{~min}$. Finalmente, las muestras se observaron con un microscopio electrónico de barrido JEOL/EO.

Para Lycopodiella s. l. y Lycopodium s. $l$. se realiza una descripción detallada de las esporas maduras de cada táxon. En el caso de las especies de Huperzia, más numerosas pero con patrones de macro-ornamentación más uniformes, se da una descripción general comparada, mencionando los caracteres más sobresalientes de cada ejemplar o ejemplares estudiados.

Las medidas del diámetro ecuatorial de las esporas y longitud de los brazos de la lesura, fueron tomadas con microscopio fotónico Nikon $80 \mathrm{i}$ eclipse ${ }^{\circledR}$, teniendo en cuenta los valores mínimos, máximos, promedio y desviación estándar en $\mu \mathrm{m}$ y un $\mathrm{n}=30$. En los táxones que presentan macro-ornamentación caviforme se tomó el diámetro de las fovéolas, la distancia 
entre fovéolas y la densidad de estas por campos de $10 \mu \mathrm{m}^{2}$ y un $\mathrm{n}=15$.

Para la descripción de la ornamentación se utilizaron los términos propuestos por Lellinger \& Taylor (1997) y Lellinger (2002), mientras que los términos monoplastidial y poliplastidial son equivalentes en español a monoplastidic y polyplastidic usados en inglés por Brown \& Lemmon (1997).

\section{RESULTADOS}

Esporocitos: Los esporocitos inmaduros de H. tetragona, H. brevifolia, P. cernua y D. thyoides son aproximadamente esféricos y se ubican dentro de la cavidad esporangial (Fig. 1 A). En esta etapa, la cubierta de los esporocitos es gruesa y presenta tres zonas de diferente electro-densidad: una interna no electro densa en contacto directo con la membrana del esporocito, una intermedia más engrosada y electro-densa, y una zona externa delgada que es la de mayor electro-densidad (Fig. 1 B). Esta cubierta carece de plasmodesmos.

El núcleo de los esporocitos inmaduros es eucromático, está en posición central y tiene uno o dos nucléolos. El citoplasma presenta abundante retículo endoplasmático con numerosos dictiosomas y no se aprecian depósitos lipídicos (Fig. 1 B). A medida que los esporocitos maduran para formar esporocitos premeióticos, se separan en la cavidad esporangial tornándose más esféricos. La membrana de los esporocitos premeióticos es sinuosa en todas las especies estudiadas y presenta proyecciones que se asocian con pequeñas zonas electrodensas que se distribuyen formando un patrón regular (Fig. 1 C, Fig. 1 D, Fig. 1 E, Fig. 1 F, Fig. 1 G). En este momento del desarrollo, el citoplasma de los esporocitos presenta abundantes depósitos lipídicos que dificultan la observación de los orgánulos. En Huperzia y Palhinhaea, una vez terminada la meiosis, en el momento en que finaliza la citocinesis y antes del depósito del exosporio, se observa que estas sinuosidades y proyecciones de la membrana de las esporas permanecen como tales en la cara distal pero no en la cara proximal, que es lisa (Fig. $1 \mathrm{H}$ ). En D. thyoides en cambio, estas sinuosidades y proyecciones de la membrana se observan en las dos caras de las esporas.

Los esporocitos premeióticos de D. thyoides son monoplastidiales, pero antes de la meiosis, el plastidio se divide quedando posicionados dos plastidios alargados, uno a cada lado del núcleo (Fig. 1 I). En cambio, $H$. tetragona, H. brevifolia y $P$. cernua son especies poliplastidiales, presentan varios plastidios ovalados y alargados con inclusiones de granos de almidón (Fig. 1 J, Fig.1 K); en estas especies los plastidios están presentes desde el momento de la formación del tejido esporógeno (Fig. $1 \mathrm{~L})$.

Tapete: El tapete de las especies poliplastidiales está formado por células globosas, de contornos subrectangulares, con numerosas vacuolas, un núcleo grande eucromático en posición central, citoplasma con numerosos plastidios esféricos, sin gránulos de almidón $\mathrm{y}$ con los grana formados por agrupaciones de 2-3 tilacoides (Fig. 2 A, Fig. B, Fig. C). En las especie monoplastidiales el tapete presenta células de contorno cuadrangular, con un núcleo grande eucromático y uno o dos nucléolos, varias vacuolas, numerosas mitocondrias y algunos plastidios alargados cerca del núcleo celular, con abundante almidón (Fig. 2 D). La pared periclinal interna del tapete en contacto con la cavidad esporangial es sinuosa en las especies monoplastidiales, con sinuosidades más amplias y complejas durante la formación de las tétradas (Fig. 2 E), momento en que se aprecian en el citoplasma abundantes cuerpos plurivesiculares y en la pared anticlinal interna vesículas de secreción que son liberadas en la cavidad esporangial (Fig. 2 F). Estas vesículas se dirigen a través del fluido de la cavidad esporangial hacia las tétradas en formación (Fig. 2 G); dan respuesta de color azul verdoso claro (turquesa) ante el TBO, y tienen propiedades de electro-densidad similares a las del exosporio (Fig. $2 \mathrm{H}$ ). Estos rasgos del tapete no se presentan en las especies poliplastidiales estudiadas, pero sí se observaron corpúsculos de esporopolenina muy próximos al tapete 


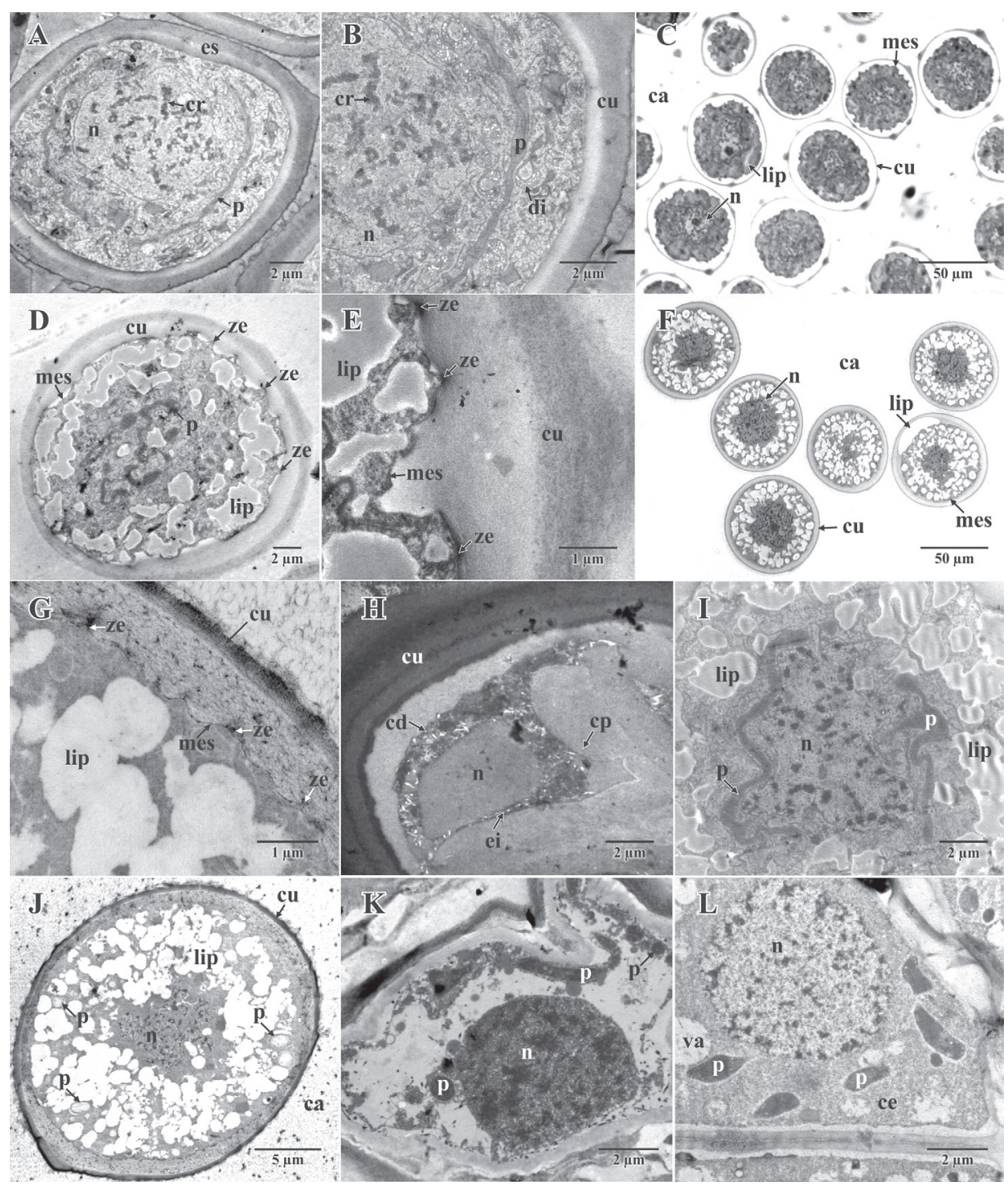

Fig. 1. Tejido esporógeno, esporocitos y esporas inmaduras de Lycopodiaceae. A-G. Caracteres estructurales y ultraestructurales de los esporocitos inmaduros y premeióticos. A-E. Diphasiastrum thyoides. F-G. Huperzia tetragona. H. Espora inmadura de Palhinhaea cernua al final de la meiosis II, sin exosporio. I. Estado monoplastidial de D. thyoides. J-K. Estados poliplastidiales de H. tetragona y P. cernua respectivamente. L. Tejido esporógeno de H. tetragona con varios plastidios ovalados largos. ca: cavidad esporangial; cd: cara distal de la espora; ce: células del tejido esporógeno; cp: cara proximal de la espora; cr: cromosomas; cu: cubierta de los esporocitos; di: dictiosomas; ei: espora inmadura sin exosporio; es: esporocitos; lip: depósitos lipídicos; mes: membranas sinuosas de los esporocitos; n: nucleo; p: plastidios; va: vacuolas; ze: zonas electro-densas asociadas a la membrana celular de los esporocitos premeióticos.

Fig. 1. Sporogenous tissue, sporocytes and immature spores of the Lycopodiaceae. A-G. Structural and ultraestuctural characters of pre-meiotic and immature sporocytes. A-E. Diphasiastrum thyoides. F-G. Huperzia tetragona. H. Immature spore of Palhinhaea cernua right at the end of meiosis II, lacking exospore. I. Monoplastidic stage of D. thyoides. J-K. Polyplastidic stages of H. tetragona and P. cernua respectively. L. Sporogenous tissue of H. tetragona with long, ovate plastids. ca: sporangial cavity; cd: distal face of the spore; ce: sporogenous tissue; cp: proximal face of spore; cr: chromosomes; cu: sporocyte coat; di: dyctiosomes; ei: immature spore lacking exospore; es: sporocytes; lip: lipid deposits; mes: sporocyte sinuous membranes; $n$ : nucleus; p: plastids; va: vacuoles; ze: electro-dense areas associated to cell membrane in pre-meiotic sporocytes. 


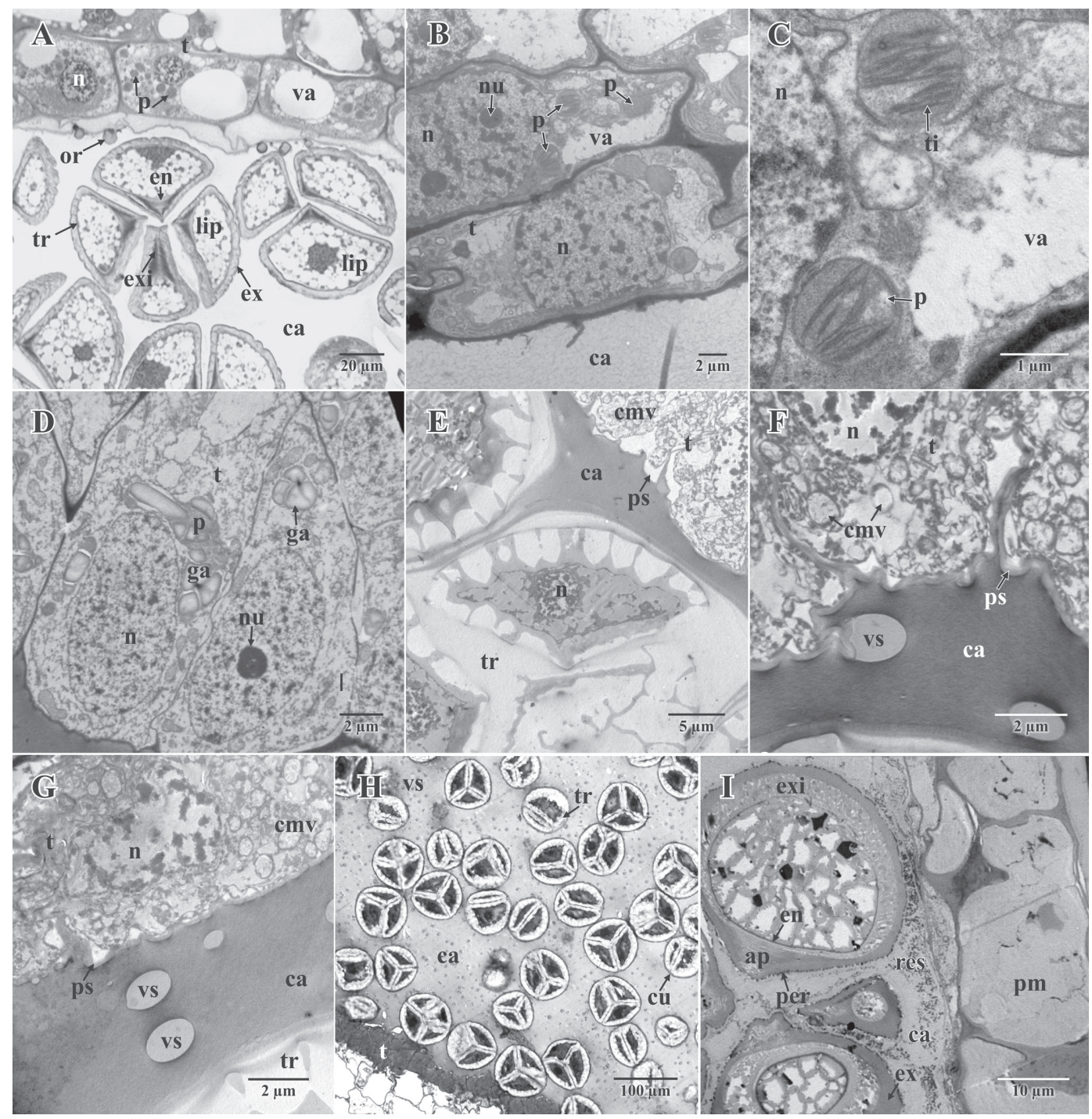

Fig. 2. Estructura y ultraestructura del tapete de Lycopodiaceae. A-C. Huperzia tetragona. D-H. Diphasiastrum thyoides. I. Palhinhaea cernua. ap: abertura esporal; ca: cavidad esporangial; cmv: cuerpos plurivesiculares; cu: cubierta de los esporocitos; en: endosporio; ex: exosporio externo; exi: exosporio interno; ga: granos de almidón; lip: depósitos lipídicos; n: nucleo; nu: nucléolos; or: corpúsculos de esporopolenina; p: plastidios; per: perisporio; pm: pared madura del esporangio; ps: paredes sinuosas del tapete; res: restos del tapete; t: tapete; ti: tilacoides; tr: tétradas; va: vacuolas; vs: vesículas de secreción.

Fig. 2. Structure and ultrastructure of the tapetum in the Lycopodiaceae. A-C. Huperzia tetragona. D-H. Diphasiastrum thyoides. I. Palhinhaea cernua. ap: spore aperture; ca: sporangial cavity; cmv: multivesicular bodies; cu: sporocyte coat; en: endospore; ex: outer exospore; exi: inner exospore; ga: starch grains; lip: lipid deposits; n: nucleus; nu: nucleoli; or: sporopollenin bodies ; p: plastids; per: perispore; pm: sporangium mature wall; ps: sinuous walls of the tapetum; res: remains of the tapetum; t: tapetum; ti: tilacoids; tr: tetrads; va: vacuoles; vs: secretion vesicles. 
(Fig. 2 A). En todos los táxones revisados el tapete degenera con la maduración de las esporas y solo persiste la pared madura del esporangio. En $P$. cernua la degradación del tapete produce restos de material granular fino muy electro-denso que se deposita sobre el exosporio externo originando el perisporio (Fig. 2 I).

Ontogenia de la pared esporal: La primera capa que se forma es el exosporio, que se deposita sobre la membrana plasmática en forma de una lámina de material no electrodenso con dos láminas electro-densas a cada lado (Fig. 3 A, Fig. 4 B). Con la maduración de las esporas, se depositan, en forma centrípeta, varias láminas consecutivas que conservan esta misma organización hasta formar una estructura multilaminar (Fig. 3 C, Fig. D) que se condensa y se vuelve homogéneamente electrodensa al madurar las esporas (Fig. 3 E, Fig. F, Fig. G). En P. cernua, durante la formación del exosporio, se observaron microtúbulos en el citoplasma de las esporas, cerca de la membrana celular de la zona adyacente a la cara distal, en relación con la macro-ornamentación (Fig. $3 \mathrm{H}$ ).

Durante el depósito del exosporio, en la cara proximal, cerca de la lesura, se forma una capa de esporopolenina difusa de apariencia fibro-granular, poco electro-densa y compacta, conocida como exosporio interno (Fig. 3 I). En $P$. cernua el exosporio interno está más engrosado que el externo y solo mantiene la apariencia fibro-granular en la zona de la apertura esporal, en tanto que en el resto de su extensión forma una capa de columnas de apariencia globular, electro-densas, anastomosantes, que dejan espacios entre sí, con la apariencia de un retículo (Fig. $3 \mathrm{~J}$ ). Las características de electro-densidad del exosporio interno y externo son similares, pero las respuestas al TBO son diferentes: azul claro (turquesa) en el caso del exosporio externo y azul oscuro en el exosporio interno (Fig. $3 \mathrm{~K}$ ). El endosporio es variable en cuanto a grosor, siendo más engrosado cerca de la abertura esporal y generalmente forma una capa electro densa granular inmediatamente debajo del exosporio interno (Fig. $3 \mathrm{~L}$ ).
El perisporio está constituido por dos capas: una interna granular muy electro densa y una externa de similar grosor pero más homogénea y menos electro densa (Fig. $3 \mathrm{~J}$ ).

La esporogénesis finaliza con la formación de las tétradas de esporas en posición tetraédrica (Fig. 4 A, Fig. 4 B, Fig. C) que permanecen unidas por la cubierta de los esporocitos hasta que maduran (Fig. 4 C). Esta cubierta se degrada en esa etapa y las esporas quedan libres en la cavidad esporangial (Fig. 4 D, Fig. E).

Macro-ornamentación y micro-ornamentación de las esporas maduras: En las Lycopodiaceae se presentan dos tipos de ornamentación: negativa caviforme y positiva muriforme. En la primera, la superficie del exosporio es perforada y presenta cavos o perforaciones más o menos redondeadas que pueden estar separados por distancias equivalentes a sus diámetros (fóveas), o separados por distancias superiores a sus diámetros (fovéolas). La ornamentación muriforme se caracteriza por la presencia de muros, que son protuberancias largas y sinuosas, regulares o irregulares, interrumpidas o bien anastomosantes que determinan aréolas más o menos claras. En las esporas rugadas los muros amplios y redondeados no son anastomosantes, mientras que en las esporas reticuladas los muros son estrechos, afilados, anastomosantes y forman aréolas definidas.

En Huperzia la macro-ornamentación es caviforme o, menos comúnmente, muriforme, y las esporas son foveoladas; raramente las fovéolas se unen o se conectan formando fósulas marginales (Fig. 5, Fig. 6, Fig. 7 y Fig. 8). En Lycopodiella, Palhinhaea y Pseudolycopodiella y unas pocas especies de Huperzia, la ornamentación es muriforme y las esporas son rugadas (Fig. 9, Fig. 10, Fig. 11), y en Austrolycopodium, Diphasium, Diphasiastrum y Lycopodium son reticuladas (Fig. 12). También se pueden observar diferencias en la ornamentación en las cara proximal, que puede ser lisa o apenas microgranular, como en especies de Huperzia, pero en táxones de otros géneros se hallan con frecuencia 

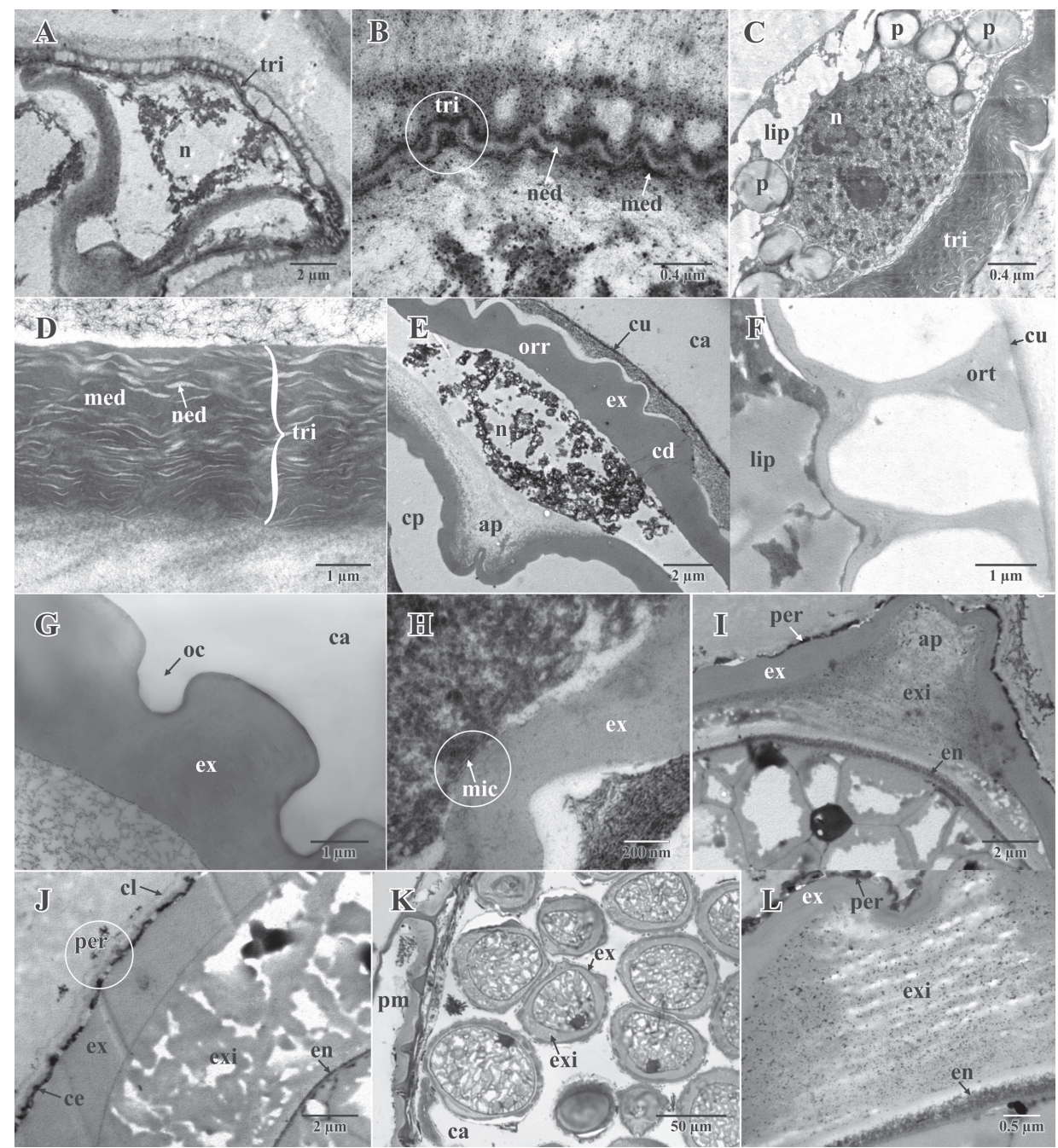

Fig. 3. Ontogenia del esporodermo de Lycopodiaceae. A-D. Depósito del exosporio externo. A-B. Palhinhaea cernua. C-D. Huperzia tetragona. E-G. Exosporio maduro de P. cernua, Diphasiastrum thyoides y Huperzia brevifolia respectivamente. H. Microtúbulos próximos al exosporio, cerca de la cara distal de las esporas, en P. cernua. I-J. Formación del exosporio interno en $P$. cernua. K. Respuestas de color del exosporio externo e interno de P. cernua ante el TBO. L. Endosporio de P. cernua. ap: abertura esporal; ca: cavidad esporangial; cd: cara distal de la espora; ce: capa electro-densa del perisporio; cl: capa no electro densa del perisporio; cp: cara proximal de la espora; cu: cubierta de los esporocitos; en: endosporio; ex: exosporio externo; exi: exosporio interno; lip: depósitos lipídicos; med: material electro-denso; mic: microtúbulos; ned: material no electro-denso; n: núcleo; oc: maro-ornamentación caviforme; orr: macro-ornamentación rugada; ort: macroornamentación reticulada; p: plastidios; per: perisporio; pm: pared madura del esporangio; tri: deposito trilaminar del exosporio externo.

Fig. 3. Ontogeny of the sporoderm of the Lycopodiaceae. A-D. Outer exospore deposition in Palhinhaea cernua (A-B) and Huperzia tetragona (C-D). E-G. Mature exospore of P. cernua, Diphasiastrum thyoides y Huperzia brevifolia respectively. H. Microtubules exospore close to distal face of spores, in $P$. cernua. I-J. Inner exospore formation in $P$. cernua. K. Staining reaction to TBO of the outer and inner exospore of $P$. cernua with TBO. L. Endospore of $P$. cernua. ap: spore aperture; ca: sporangial cavity; cd: spore distal face; ce: electrodense perispore layer; cl: no electrodense perispore layer; cp: spore proximal face; cu: sporocyte coat; en: endospore; ex: outer exospore; exi: inner exospore; lip: lipid deposits; med: electrodense material; mic: microtubules; ned: non electrodense material; n: nucleus; oc: caviform macro-ornamentation; orr: rugate macro-ornamentation; ort: reticulate macro-ornamentation; p: plastids; per: perispore; pm: sporangium mature wall; tri: 3- laminated outer exospore deposit. 

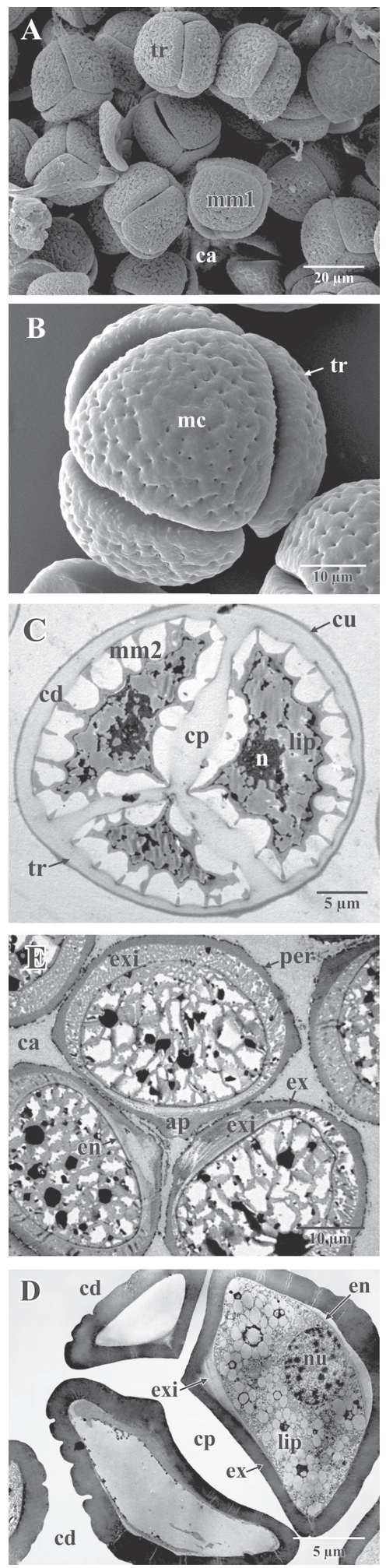

microgránulos, microarrugas y orbículas, así también como diferencias en el desarrollo y extensión del retículo proximal en especies y subespecies de Austrolycopodium, Diphasium, Diphasiastrum y Lycopodium. En el cuadro 1 se resumen los caracteres de la ornamentación de la cara proximal y distal de las esporas de cada táxon estudiado.

\section{Macro-ornamentación caviforme: espo-} ras foveoladas: Las esporas de Huperzia son tetraédricas, con el contorno ecuatorial subtriangular a subcircular, con lados curvos y ángulos redondeados.

La ornamentación que se presenta en la cara distal es negativa, caviforme, con cavos o fovéolas de contorno circular y diámetro variable (desde 1.5 hasta de $3.5 \mu \mathrm{m}$ ) separados por una distancia mayor que sus diámetros (Fig. 5, Fig. 6, Fig. 7 y Fig. 8). La superficie entre fovéolas es lisa, con microarrugas o microgránulos (Cuadro 1).

Las fovéolas son muy marcadas y se distribuyen regularmente en toda la superficie de la cara distal, incluyendo el centro de la espora pero se unen en el área cercana al ecuador formando fósulas, como en $H$. molongensis (Fig. 5 J, Fig. 5 K, Fig. 5 L); con menor diámetro, se presentan hacia el ecuador de la cara distal o hacia el centro de la cara distal de una misma

Fig. 4. Tétradas de esporas de Lycopodiaceae. A-B. Palhinhaea cernua y Huperzia callitrichifolia. C-E. Diphasiastrum thyoides, Huperzia brevifolia y P. cernua respectivamente. ap: abertura; ca: cavidad esporangial; cd: cara distal de las esporas; cp: cara proximal de las esporas; cu: cubierta de los esporocitos; en: endosporio; ex: exosporio externo; exi: exosporio interno; lip: depósitos lipídicos; mc: ornamentación caviforme; $\mathrm{mm} 1$ : ornamentación muriforme rugada; $\mathrm{mm} 2$ : ornamentación muriforme reticulada; $n$ : núcleo; per: perisporio; tr: tétradas. Fig. 4. Spore tetrads of the Lycopodiaceae. A-B. Palhinhaea cernua and Huperzia callitrichifolia. C-E. Diphasiastrum thyoides, $H$. brevifolia y $P$. cernua respectively. ap: aperture; ca: sporangial cavity; cd: spore distal face; cp: spore proximal face; cu: sporocyte coat; en: endospore; ex: outer exospore; exi: inner exospore; lip: lipid deposits; mc: caviform ornamentation; $\mathrm{mm} 1$ : muriform, rugate ornamentación; mm2: muriform, reticulate ornamentation; $\mathrm{n}$ : nucleus; per: perispore; tr: tetrads. 


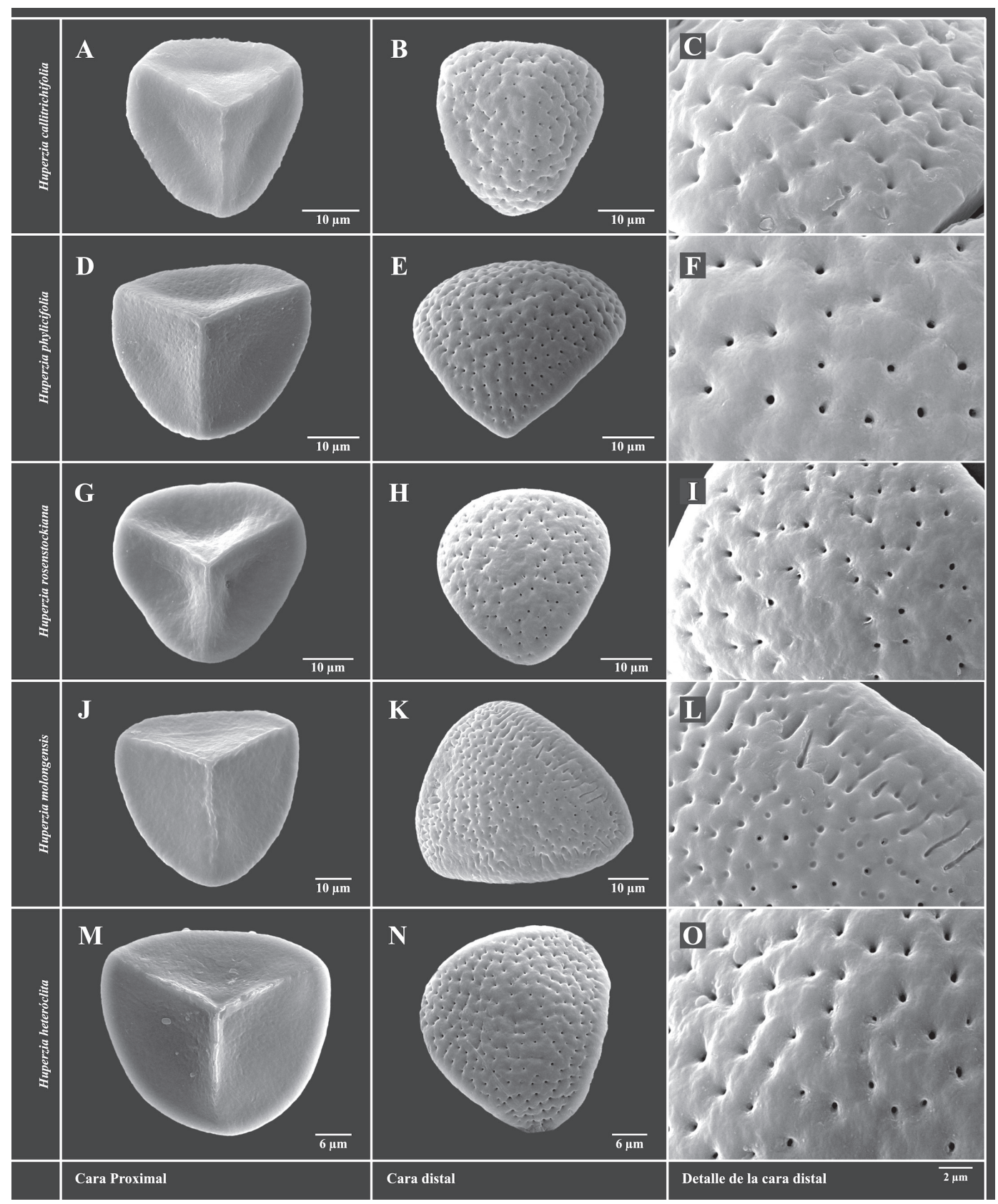

Fig. 5. Ornamentación caviforme, negativa, en especies de Huperzia: esporas foveoladas, superficie entre cavos lisa. Fig. 5. Caviform, negative ornamentation of Huperzia species: foveolate spores, smooth surface between cavi. 


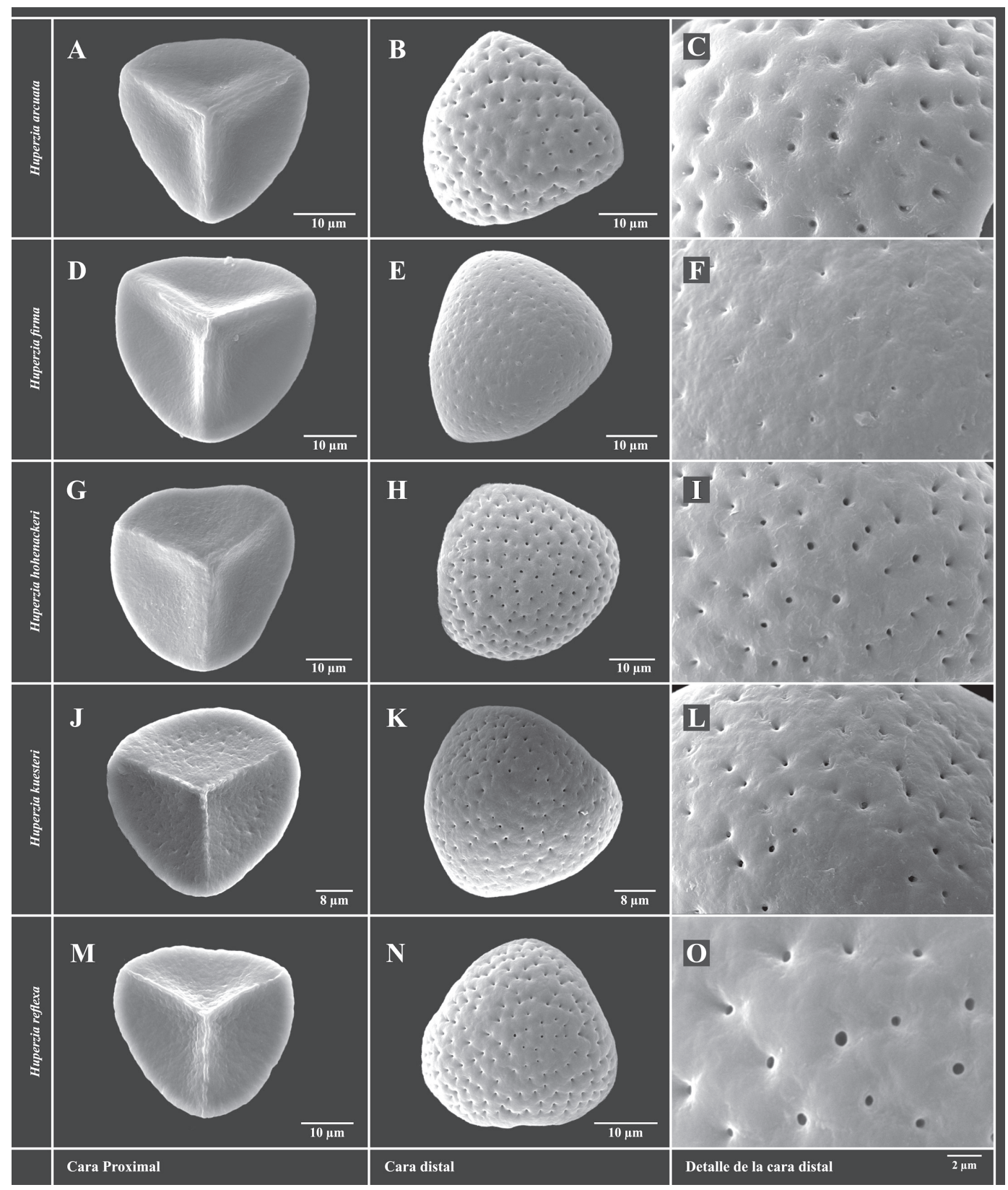

Fig. 6. Ornamentación caviforme, negativa, en especies de Huperzia: esporas foveoladas, superficie entre cavos lisa. Fig. 6. Caviform, negative ornamentation of Huperzia species: foveolate spores, smooth surface between cavi.

espora, como en H. heteroclita (Fig. 5 M, Fig. N, Fig. O) o bien se distribuyen en la cara distal de la espora, en forma circular y dejan una zona central lisa, sin perforaciones, como en H. rosenstockiana (Fig. 5 G, Fig. 5H, Fig. 5I) y
H. kuesteri (Fig. 6 J, Fig. 6 K, Fig. 6L). La distribución es muy uniforme en $H$. hohenackeri (Fig. 6 G, Fig. 6H, Fig. 6I), H. reflexa (Fig. 6 M, Fig. Fig. 6N, Fig. 6O) y H. crassa, en esta especie, con el diámetro comparativamente 


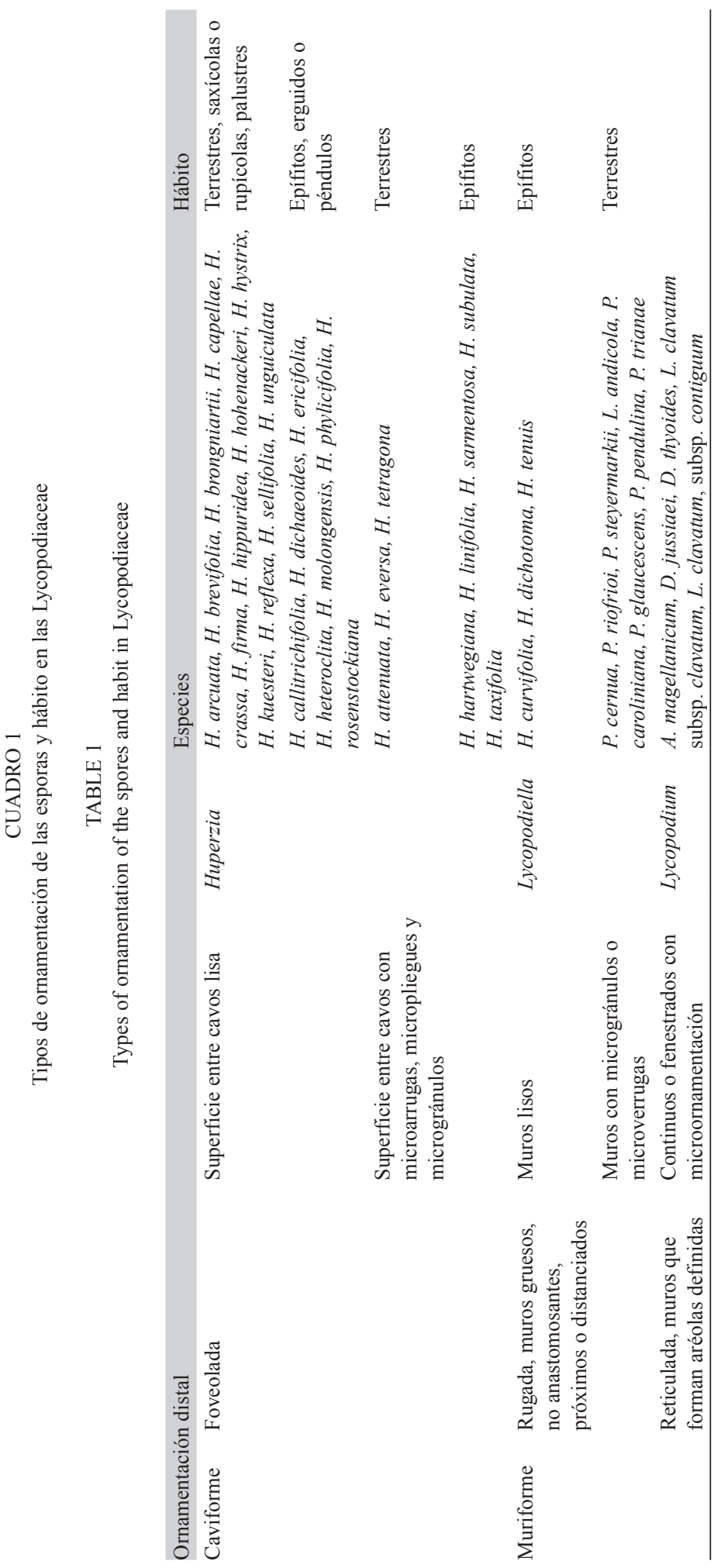




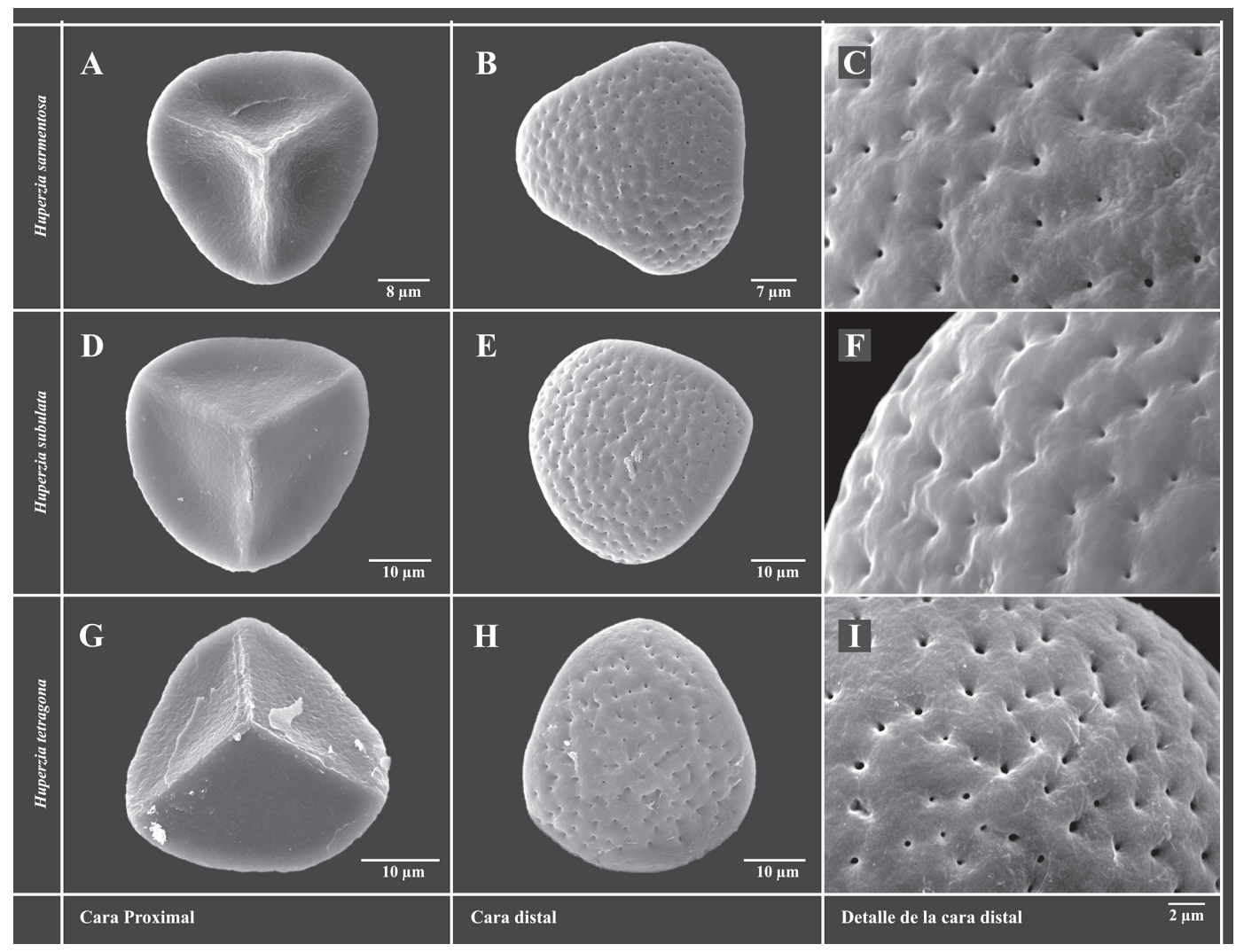

Fig. 7. Ornamentación caviforme, negativa, en especies de Huperzia: esporas foveoladas, superficie entre cavos con microornamentación.

Fig. 7. Caviform, negative ornamentation of Huperzia species: foveolate spores, micro-ornamentated surface between cavi.

más pequeño. Con diámetros y disposición muy regulares se presentan también en esporas con exosporio con superficie microgranular, como es el caso de H. kuesteri (Fig.6 J, Fig. 6K, Fig. 6L) у H. linifolia (Fig. 8 J, Fig. 8K, Fig. 8L), o con superficie rugulada, como en H. hartwegiana (Fig. 8 A, Fig. 8B, Fig. 8C). La cara proximal es lisa, sin fovéolas ni muros. La lesura trilete llega generalmente hasta el ecuador de la espora y puede ser lisa o tener brazos ondulado-crenados (Fig. 5, Fig. 6, Fig. 7 y Fig. 8).

En general, el promedio de los diámetros ecuatoriales de las esporas en este grupo de plantas varía entre 31-61 $\mu \mathrm{m}$. En especies terrestres como $H$. arcuata, $H$. brevifolia, $H$. brongniartii, H. capellae, H. crassa, H. firma,
H. hippuridea, H. hohenackeri, H. hystrix, $H$. kuesteri, H. reflexa, H. sellifolia, H. unguiculata esa variación va de 33 hasta $50 \mu \mathrm{m}$; en especies epífitas con esporas cuya superficie entre fovéolas es lisa, como H. callitrichifolia, $H$. dichaeoides, $H$. ericifolia, $H$. heteroclita, $H$. molongensis, $H$. phylicifolia, $H$. rosenstockia$n a$, las medidas van desde 31 hasta $61 \mu \mathrm{m}$ y en las epífitas con superficie rugulada, como $H$. hartwegiana, H. linifolia. H. sarmentosa, $H$. subulata, H. taxifolia, los tamaños se encuentran entre 33 y $50 \mu \mathrm{m}$. En una especie terrestre y tres epífitas con esporas foveoladas, $H$. firma, $H$. molongensis, H. linifolia y H. subulata, se encontraron las esporas con los mayores tamaños según el diámetro ecuatorial $(48-61 \mu \mathrm{m})$. El diámetro de las fovéolas y la densidad por 


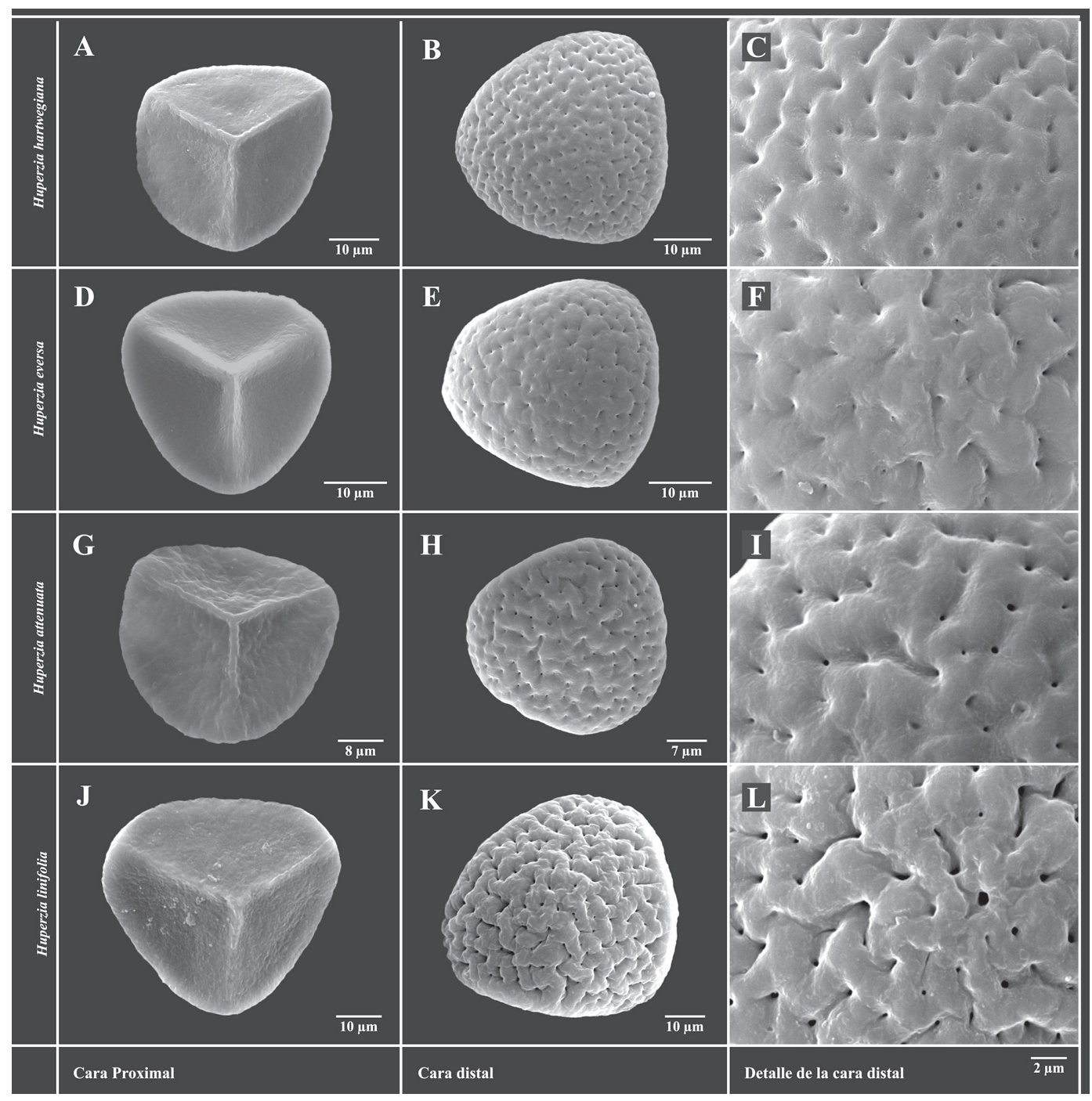

Fig. 8. Ornamentación caviforme, negativa, en especies de Huperzia: esporas foveoladas, superficie entre cavos con microornamentación.

Fig. 8. Caviform, negative ornamentation of Huperzia species: foveolate spores, micro-ornamentated surface between cavi.

campo de $10 \mu \mathrm{m}^{2}$ son poco variables, y sólo se observaron mayores densidades en $H$. dichaeoides, $H$. hartwegiana y $H$. heteroclita. La longitud de los brazos de la lesura varía en un rango de 21-34 $\mu \mathrm{m}$ (Cuadro 2).

\section{Macro-ornamentación muriforme:} en esporas rugadas: De todas las especies de Huperzia analizadas, solamente $H$. tenuis, $H$. curvifolia y $H$. dichotoma presentan ornamentación muriforme. Las esporas son generalmente tetraédricas, triletes, anisopolares, con el contorno ecuatorial subtriangular, y los muros son bajos, no anastomosantes, con micropliegues, microperforaciones y microverrugas sobre la superficie (Fig. 9 A, Fig. B, Fig. C, Fig. D, Fig. E, Fig. F, Fig. G, Fig. H, Fig. I). En Lycopodiella s. l. las esporas son tetraédricas, triletes, anisopolares, radiosimétricas, con ornamentación muriforme diferente en las 
CUADRO 2

Dimensiones de las esporas, longitud de la lesura, diámetro, densidad y distancia entre foveolas en especies de Huperzia

TABLE 2

Dimensions of spores, laesure length, diameter, density and distance between foveolae in species of genus Huperzia

\begin{tabular}{|c|c|c|c|c|c|}
\hline Especies & $\begin{array}{l}\text { Diámetro ecuatorial } \\
\text { esporas }(*)\end{array}$ & $\begin{array}{l}\text { Diámetro f } \\
\text { oveolas }(*)\end{array}$ & $\begin{array}{c}\text { Densidad } \\
\text { foveolas }(* *)\end{array}$ & $\begin{array}{l}\text { Distancia entre } \\
\text { foveolas }(*)\end{array}$ & $\begin{array}{l}\text { Longitud } 1 \\
\text { esura }(*)\end{array}$ \\
\hline H. arcuata & $(28) 33(36) \pm 1.32$ & (0.3) $0.5(0.6)$ & $10-11$ & $3-4$ & (16) $18(20) \pm 1.14$ \\
\hline H. attenuata & (31) $33(34) \pm 1.63$ & $(0.2) 0.4(0.6)$ & $10-13$ & $2-4$ & (18) 19 (21) \pm 0.61 \\
\hline H. brevifolia & $(44) 47(50) \pm 1.44$ & (0.4) $0.5(0.6)$ & $12-15$ & $2-3$ & (22) $24(26) \pm 0.76$ \\
\hline H. brongniartii & (29) $32(34) \pm 1.40$ & (0.3) $0.4(0.6)$ & $11-13$ & $3-4$ & (15) $16(18) \pm 0.90$ \\
\hline H. callitrichifolia & (29) $31(33) \pm 1.23$ & $(0.3) 0.4(0.5)$ & $11-16$ & $2-3$ & (17) $18(20) \pm 0.83$ \\
\hline H. capellae & (31) $33(35) \pm 1.04$ & $(0.4) 0.5(0.6)$ & $10-13$ & $3-4$ & (16) 18 (19) \pm 0.84 \\
\hline H. crassa & $(40) 43(46) \pm 1.68$ & $(0.3) 0.5(0.7)$ & $9-14$ & $3-4$ & (20) $21(22) \pm 0.44$ \\
\hline H. dichaeoides & (37) $39(41) \pm 0.94$ & $(0.2) 0.4(0.5)$ & $18-25$ & $2-3$ & (19) $20(21) \pm 0.74$ \\
\hline H. ericifolia & $(30) 33(36) \pm 1.58$ & $(0.2) 0.35(0.4)$ & $13-17$ & $2-3$ & (15) $17(18) \pm 1.08$ \\
\hline H. eversa & $(38) 40(42) \pm 1.23$ & $(0.2) 0.4(0.5)$ & $11-15$ & $2-4$ & (19) $21(23) \pm 1,06$ \\
\hline H. firma & $(47) 50(53) \pm 1.75$ & $(0.3) 0.4(0.5)$ & $8-11$ & $3-4$ & (21) $24(25) \pm 1.31$ \\
\hline H. hartwegiana & $(42) 44(45) \pm 0.95$ & $(0.2) 0.4(0.6)$ & $15-21$ & $2-3$ & (20) $22(23) \pm 0.63$ \\
\hline H. heteroclita & (32) $34(35) \pm 0.65$ & $(0.3) 0.4(0.5)$ & $18-22$ & $2-3$ & (15) 18 (19) \pm 0.81 \\
\hline H. hippuridea & $(38) 40(41) \pm 1.19$ & (0.3) $0.5(0.7)$ & $17-21$ & $2-2.5$ & (17) $19(21) \pm 1.12$ \\
\hline H. hohenackeri & $(42) 44(45) \pm 0.92$ & $(0.5) 0.6(0.7)$ & $9-11$ & $3-4$ & $(21) 22(23) \pm 0.69$ \\
\hline H. hystrix & (28) $31(33) \pm 1.19$ & $(0.2) 0.28(0.3)$ & $12-16$ & $2-3$ & (13) $15(16) \pm 0.81$ \\
\hline H. kuesteri & $(43) 45(47) \pm 1.07$ & (0.3) $0.4(0.6)$ & $8-11$ & $3-4$ & (20) $22(23) \pm 0.87$ \\
\hline H. linifolia & (47) $50(52) \pm 1.24$ & $(0.3) 0.4(0.5)$ & $17-21$ & $2-2.5$ & (24) $26(27) \pm 1,44$ \\
\hline H. molongensis & $(58) 61(63) \pm 1.76$ & $(0.4) 0.5(0.6)$ & $19-20$ & $2-3$ & (28) $30(32) \pm 1.27$ \\
\hline H. phylicifolia & (39) $41(50) \pm 1.89$ & $(0.3) 0.4(0.5)$ & $15-21$ & $3-3.5$ & (17) $21(26) \pm 1.30$ \\
\hline H. reflexa & (37) $39(47) \pm 1.89$ & $(0.3) 0.4(0.5)$ & $16-20$ & $2-3$ & (18) $20(24) \pm 1.19$ \\
\hline H. rosenstockiana & $(38) 40(51) \pm 2.43$ & $(0.3) 0.4(0.5)$ & $13-17$ & $2-3$ & (20) $22(29) \pm 1.55$ \\
\hline H. sarmentosa & (34) $36(45) \pm 1.96$ & $(0.2) 0.3(0.35)$ & $15-20$ & $2-3$ & $(18) 19(25) \pm 1.09$ \\
\hline H. sellifolia & (32) $33(35) \pm 1.04$ & (0.3) $0.4(0.6)$ & $11-13$ & $3-4$ & (16) $18(20) \pm 0.82$ \\
\hline H. subulata & $(47) 48(50) \pm 0.79$ & (0.2) $0.3(0.4)$ & $13-15$ & $2-3$ & (23) $25(26) \pm 0.76$ \\
\hline H. taxifolia & (31) $32(34) \pm 0.78$ & $(0.2) 0.4(0.6)$ & $20-24$ & $2-3$ & (15) $16(18) \pm 0.84$ \\
\hline H. tetragona & (40) $41(44) \pm 0.93$ & $(0.3) 0.4(0.6)$ & $13-16$ & $2-3$ & (19) $20(22) \pm 0.79$ \\
\hline H. unguiculata & (39) $40(43) \pm 1.13$ & $(0.3) 0.5(0.8)$ & $11-13$ & $3-4$ & (19) $20(22) \pm 0.72$ \\
\hline
\end{tabular}

(*) En $\mu \mathrm{m}$

(**) Medida en campos de $10 \mu \mathrm{m}^{2}$

caras distal y proximal, prevaleciendo el tipo rugado en la cara distal. El contorno ecuatorial es casi circular, con muros espaciados o próximos, generalmente prominentes, como lomos o pliegues curvos a casi angulosos, no anastomosantes o, más raramente, anastomosantes y continuos, pero sin formar aréolas y sin un patrón reticulado (Fig. 10, Fig. 11). La superficie de los muros es lisa y en algunos casos presenta micro-ornamentación granular o microverrugas. Los muros son lisos en $P$. steyermarkii, P. cernua y P. riofrioi (Fig. 10 A, Fig. 10 B, Fig. 10 C, Fig. 10 D, Fig. 10 E, Fig. 10 F, Fig. 10 G, Fig. 10 H, Fig. 10 I) y tienen micro-ornamentación granular en $L$. andicola y P. caroliniana (Fig. 11 A, Fig. 11 B, Fig. 11 C, Fig. 11 D, Fig. 11 E, Fig. 11 F). En P. pendulina la micro-ornamentación es densamente microgranular (Fig. 11 G, Fig. 11 H, Fig. 11I), en tanto que en $P$. trianea y $P$. glaucescens los 


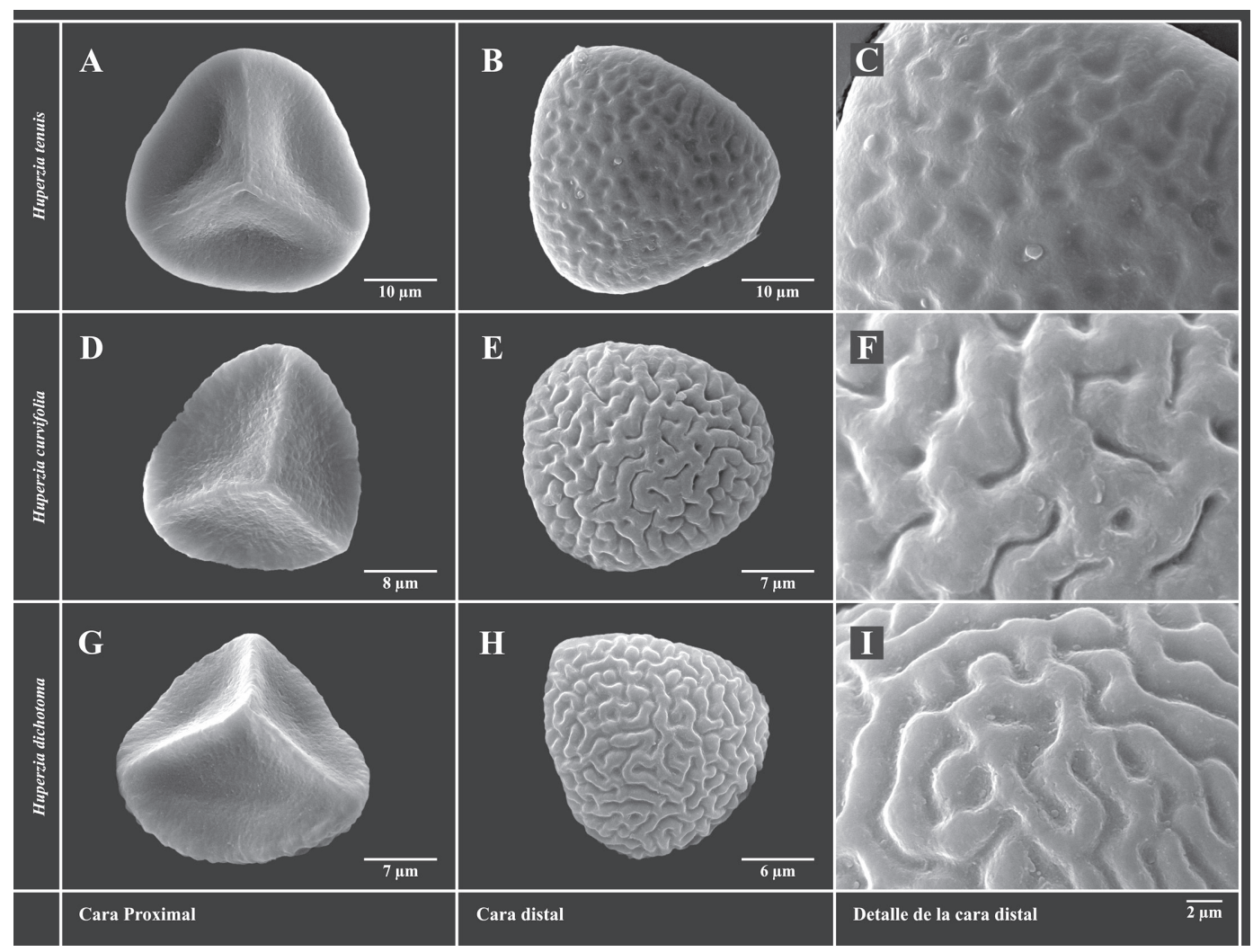

Fig. 9. Ornamentación muriforme en especies de Huperzia: esporas rugadas, superficie de los muros lisa o con microgránulos y orbículas dispersas.

Fig. 9. Muriforme ornamentation of Huperzia species: rugate spores, smooth or micro granulated surface of muri, with scattered orbicules.

muros tienen microverrugas (Fig. $11 \mathrm{~J}$, Fig. 11 K, Fig. 11 L, Fig. 11 M, Fig. 11 N, Fig. 11 O). La cara proximal es lisa, con microgránulos, micropliegues o con microverrugas como en $P$. trianea, y en algunas especies como $L$. andicola es rugulada o rugada. La lesura es labiada, prominente y los brazos no llegan al ecuador (Cuadro 3).

En general se presenta un cíngulo ecuatorial marcado, que es liso y tiene el aspecto de un lomo convexo o bien es ornamentado, ondulado crenado y claramente distintivo.

En esporas rugadas el promedio de los diámetros ecuatoriales varía con un rango de 28-45 $\mu \mathrm{m}$ (Cuadro 3), y las esporas más grandes se presentaron en Lycopodiella (L. andicola y P. glaucescens).
La variación observada en esporas rugadas se da a continuación, con una descripción detallada de cada táxon.

\section{Huperzia}

\section{Huperzia tenuis}

(Fig. 9 A, Fig. 9B, Fig. C).

Diámetro ecuatorial de (32) 33 (34) \pm $0.43 \mu \mathrm{m}$. Cara distal con muros bajos, curvos, hasta de $1.5-2 \mu \mathrm{m}$, con algunas microverrugas espaciadas, los muros bastante uniformes delimitando depresiones circulares muy regulares. Lesura trilete que llega hasta el ecuador de la espora, con brazos lisos de (15) 17 (18) \pm $0.44 \mu \mathrm{m}$. 


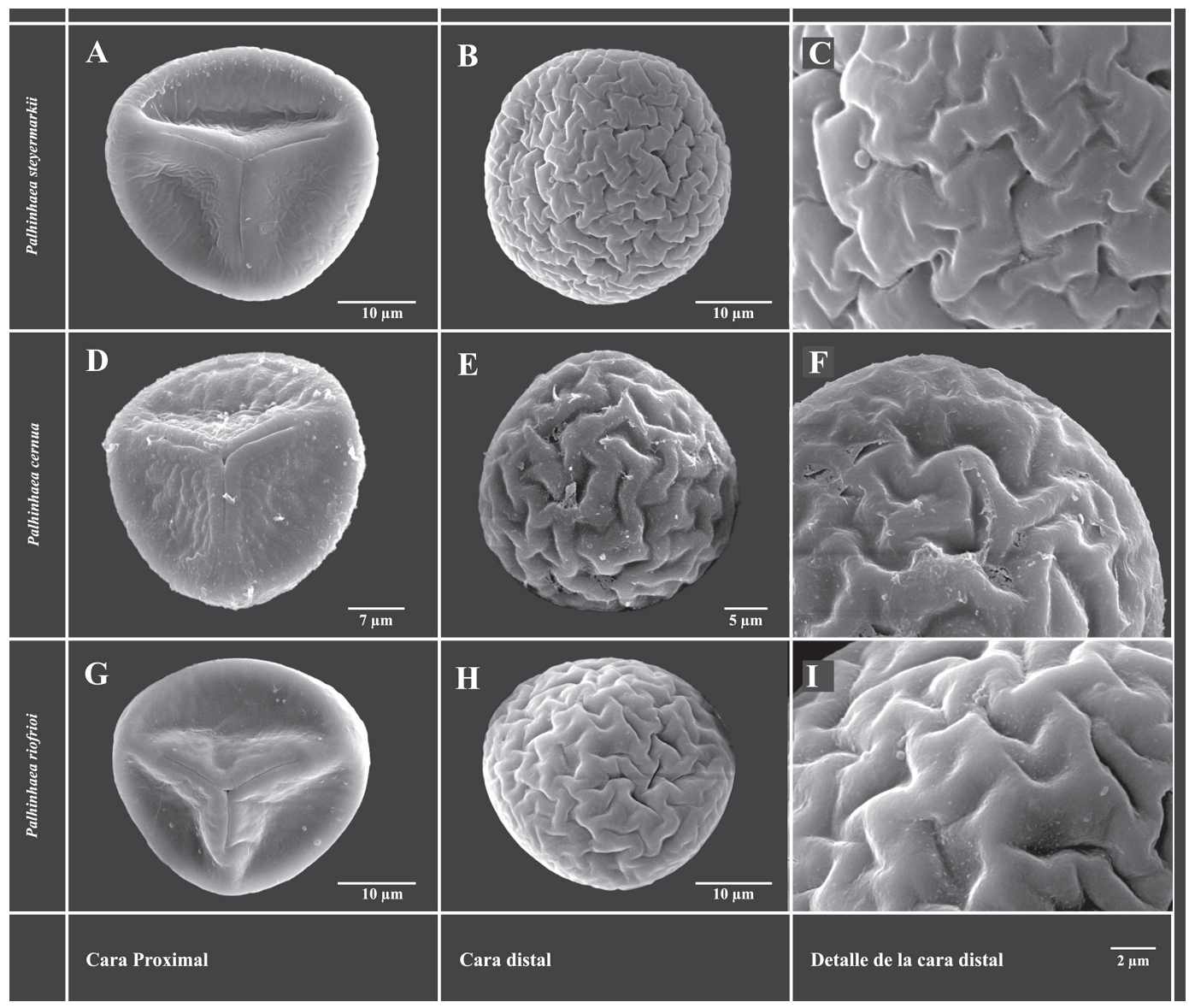

Fig. 10. Esporas con ornamentación muriforme rugada en especies de Lycopodiella s. $l$.

Fig. 10. Muriform, rugate spores of Lycopodiella s.l. species.

\section{Huperzia curvifolia}

(Fig. 9 D, Fig. E, Fig. F).

Diámetro ecuatorial de (26) 28 (31) \pm $1.28 \mu \mathrm{m}$. Cara distal con muros bajos, próximos, redondeados, hasta de $3-5 \mu \mathrm{m}$, con micropliegues en toda la superficie. Cara proximal rugada. Lesura trilete que llega hasta el ecuador de la espora, con brazos lisos o algo onduladocrenados (13) $16(17) \pm 1.24 \mu \mathrm{m}$.

\section{Huperzia dichotoma}

(Fig. 9 G, Fig. 9H, Fig. 9I).

Diámetro ecuatorial de (32) 33 (34) $\pm 0.75 \mu \mathrm{m}$. Cara distal con muros bajos distanciados, con lomos redondeados, hasta de $1.5-2 \mu \mathrm{m}$, con microperforaciones en toda la superficie y microverrugas en la base. Lesura trilete que llega hasta el ecuador de la espora, con brazos lisos de (16) 17 (18) $\pm 0.62 \mu \mathrm{m}$.

\section{Lycopodiella s. 1.}

\section{Palhinhaea steyermarkii}

(Fig. 10 A, Fig. 10 B, Fig. 10 C).

Contorno ecuatorial subcircular con cíngulo no ornamentado. Diámetro ecuatorial de (33) $35(37) \pm 1.01 \mu \mathrm{m}$. Cara distal rugada con pliegues bajos, anchos, gruesos y con forma de lomos muy próximos de recorrido anguloso. 
CUADRO 3

Diámetro ecuatorial y longitud de la lesura en esporas con ornamentación muriforme rugada y reticulada.

TABLE 3

Equatorial diameter and length of laesure in spores with muriform, rugate and reticulate ornamentation.

\begin{tabular}{|c|c|c|c|c|}
\hline \multicolumn{2}{|c|}{ Ornamentación } & Especies & Diámetro ecuatorial en $\mu \mathrm{m}$ & Longitud de la lesura en $\mu \mathrm{m}$ \\
\hline \multirow[t]{11}{*}{ Rugada } & Huperzia & H. curvifolia & (26) $28(31) \pm 1.28$ & (13) $16(17) \pm 1.24$ \\
\hline & & H. dichotoma & (32) $33(34) \pm 0.75$ & (16) $17(18) \pm 0.62$ \\
\hline & & H. tenuis & (32) $33(34) \pm 0.43$ & (15) $17(18) \pm 0.44$ \\
\hline & Lycopodiella & L. andicola & (39) $45(49) \pm 2.32$ & (13) $16(19) \pm 1.83$ \\
\hline & & P. сегпиа & (28) $31(34) \pm 1.71$ & (8) $11(13) \pm 1.35$ \\
\hline & & P. glaucescens & (34) $40(43) \pm 2.37$ & (9) $12(15) \pm 1.30$ \\
\hline & & P. pendulina & (33) $38(41) \pm 2.25$ & (9) $12(13) \pm 1.14$ \\
\hline & & P. riofrioi & (35) $37(41) \pm 2.25$ & (9) $11(12) \pm 0.99$ \\
\hline & & P. steyermarkii & (33) $35(37) \pm 1.01$ & (11) $14(18) \pm 1.51$ \\
\hline & & P. trianae & (32) $37(40) \pm 1.9$ & (9) $11(12) \pm 1.05$ \\
\hline & & P. caroliniana & (34) $37(40) \pm 1.52$ & (10) $12(14) \pm 1.16$ \\
\hline \multirow[t]{5}{*}{ Reticulada } & Lycopodium & A. magellanicum & (33) $34(36) \pm 1.05$ & (17) $19(21) \pm 1.11$ \\
\hline & & D. jussiaei & (34) $36(37) \pm 0.08$ & (16) $18(20) \pm 1.23$ \\
\hline & & D. thyoides & (35) $35(37) \pm 1.19$ & (13) $16(18) \pm 1.36$ \\
\hline & & L. clavatum subsp. clavatum & (31) $33(35) \pm 1.38$ & (11) $12(14) \pm 0.95$ \\
\hline & & L. clavatum subsp. contiguum & (33) $37(39) \pm 1.20$ & (15) $19(23) \pm 2.20$ \\
\hline
\end{tabular}

Cara proximal lisa a rugulado-microplegada. Lesura labiada, labios gruesos, prominentes y lisos de (11) $14(18) \pm 1.51 \mu \mathrm{m}$.

\section{Palhinhaea cernua}

(Fig. 10 D, Fig. 10 E, Fig. F).

Contorno ecuatorial subcircular con cíngulo liso. Diámetro ecuatorial de (28) 31 (34) $\pm 1.71 \mu \mathrm{m}$. Cara distal rugada con pliegues anchos hasta de $3 \mu \mathrm{m}$, altos hasta de $1.5 \mu \mathrm{m}$, gruesos, irregulares y con forma de lomos redondeados. Cara proximal rugulada. Lesura labiada de (8) $11(13) \pm 1.35 \mu \mathrm{m}$.

\section{Palhinhaea riofrioi}

(Fig. 10 G, Fig. H, Fig. I).

Contorno ecuatorial subcircular con cíngulo ondulado-crenado o rugulado. Diámetro ecuatorial de (35) 37 (41) $\pm 2.25 \mu \mathrm{m}$. Cara distal rugada con pliegues anchos y gruesos, curvos a casi angulosos, hasta de 3-3.5 $\mu \mathrm{m}$ de anchura, con lomos redondeados, con microverrugas y orbículas superficiales dispersas. Cara proximal rugulada, con orbículas grandes, hasta de $1 \mu \mathrm{m}$ de diámetro, de distribución irregular. Lesura labiada, con labios gruesos y prominentes de (9) $11(12) \pm 0.99 \mu \mathrm{m}$.

\section{Lycopodiella andicola}

(Fig. 11 A, Fig. 11 B, Fig. 11C).

Contorno ecuatorial subcircular con cíngulo ondulado-crenado a rugulado. Diámetro ecuatorial de (39) 45 (49) $\pm 2.32 \mu \mathrm{m}$. Cara distal rugada con muros anchos hasta de $1.8 \mu \mathrm{m}$, gruesos hasta de $2 \mu \mathrm{m}$ y con forma de lomos redondeados, con microgránulos y micropliegues en toda la superficie. Cara proximal rugulada. Lesura labiada, labios gruesos prominentes y lisos de (13) $16(19) \pm 1.83 \mu \mathrm{m}$.

\section{Pseudolycopodiella caroliniana}

(Fig. 11 D, Fig. 11 E, Fig. 11 F).

Contorno ecuatorial subcircular con cíngulo ondulado-crenado o rugado. Diámetro 


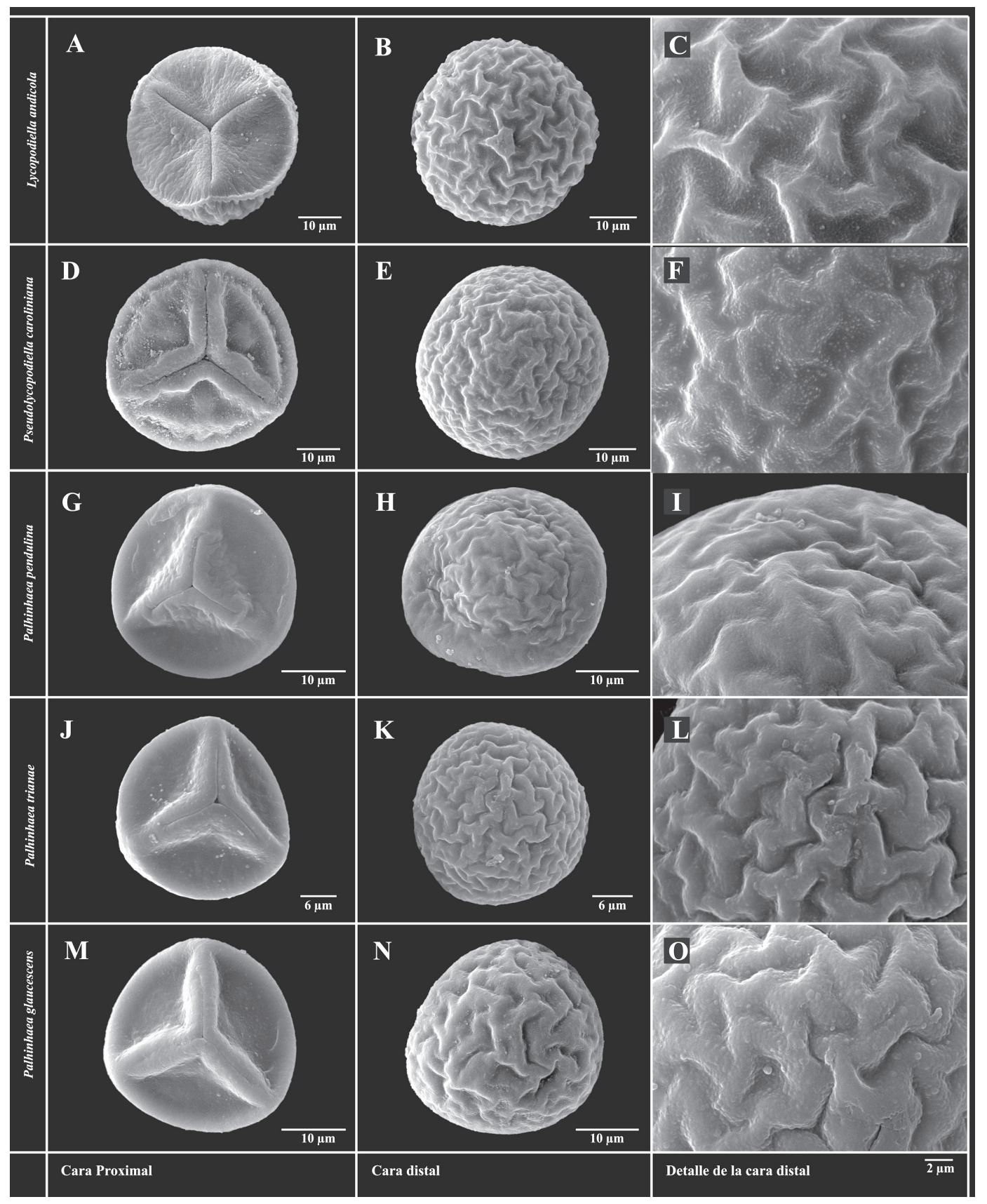

Fig. 11. Esporas con ornamentación muriforme rugada en especies de Lycopodiella s. $l$.

Fig. 11. Muriform, rugate ornamentation of Lycopodiella s.l. species. 


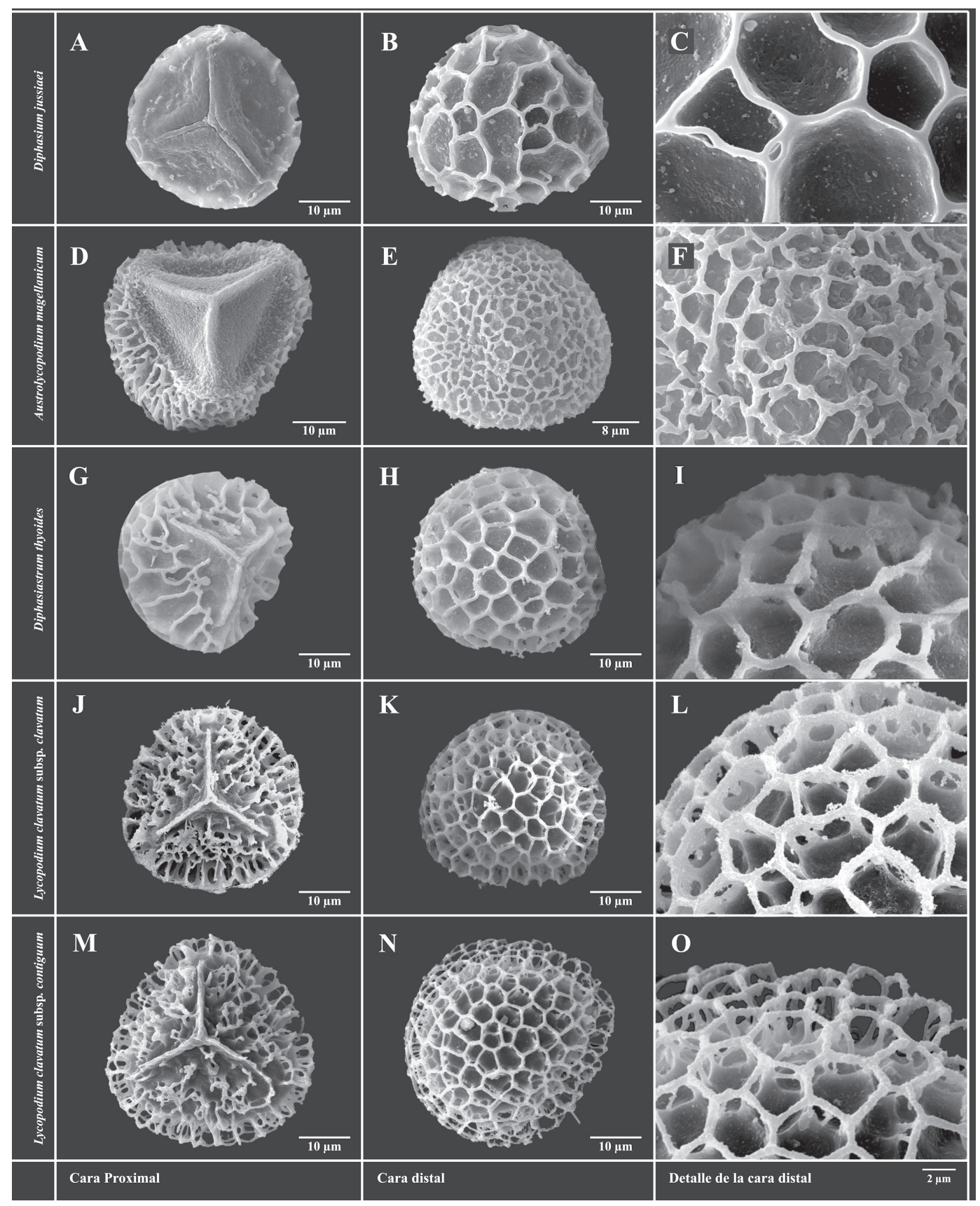

Fig. 12. Esporas con ornamentación muriforme reticulada en especies de Lycopodium $s . l$.

Fig. 12. Muriform, reticulate spores of Lycopodium s.l. species. 
ecuatorial de (34) $37(40) \pm 1.52 \mu \mathrm{m}$. Cara distal rugada con pliegues anchos, hasta de $2.5-3 \mu \mathrm{m}$ pero no muy altos, hasta de $0.5 \mu \mathrm{m}$, con lomos redondeados; orbículas y microgránulos densamente distribuidos en la superficie y la base de los muros. Cara proximal rugulado-plegada, también con microgránulos. Lesura labiada, labios gruesos y prominentes, con la superficie rugulada y con pliegues, de (10) 12 (14) \pm $1.16 \mu \mathrm{m}$.

\section{Palhinhaea pendulina}

(Fig. 11 G, Fig. 11 H, Fig. 11 I).

Contorno ecuatorial subcircular con cíngulo ondulado-crenado o rugulado. Diámetro ecuatorial de (33) $38(41) \pm 2.25 \mu \mathrm{m}$. Cara distal rugada con pliegues anchos y gruesos, hasta de $2.5 \mu \mathrm{m}$, bajos, raramente de más de $0.5 \mu \mathrm{m}$, con forma de lomos redondeados o angulosos, densamente microgranulares en la base. Cara proximal rugulada. Lesura labiada, labios gruesos y prominentes, de (9) 12 (13) $\pm 1.14 \mu \mathrm{m}$.

\section{Palhinhaea trianae}

(Fig. 11 J, Fig. 11 K, Fig. 11 L).

Contorno ecuatorial subcircular con cíngulo no ornamentado. Diámetro ecuatorial de (32) $37(40) \pm 1.9 \mu \mathrm{m}$. Cara distal rugada con muros anchos y gruesos, hasta de $1.8 \mu \mathrm{m}$ y con forma de lomos curvos con micro-ornamentación granular. Cara proximal lisa con orbículas dispersas de no más de $0.3-0.4 \mu \mathrm{m}$. Lesura labiada de (9) 11 (12) $\pm 1.05 \mu \mathrm{m}$.

\section{Palhinhaea glaucescens}

(Fig. 11 M, Fig. 11 N, Fig. 11 O)

Contorno ecuatorial subcircular con cíngulo no ornamentado. Diámetro ecuatorial de (34) $40(43) \pm 2.37 \mu \mathrm{m}$. Cara distal rugada con pliegues anchos hasta de $4-4.5 \mu \mathrm{m}$, con orbículas y microverrugas entre los pliegues. Cara proximal lisa a rugulada, con orbículas distribuidas irregularmente. Lesura labiada, labios gruesos y prominentes de (9) $12(15) \pm 1.30 \mu \mathrm{m}$.
Macro-ornamentación muriforme en esporas reticuladas: Las esporas de Lycopodium $s$. $l$. son globoso-tetraédricas, con la cara distal curva y la proximal con tres áreas planas a los lados de la lesura trilete. El contorno distal es circular en todas las especies examinadas menos en A. magellanicum, en la que es subcircular a subtriangular con lados curvos y ángulos redondeados (Fig. 12).

El retículo distal está formado por muros bajos que se anastomosan irregularmente y presentan muros cortos libres hacia el interior de aréolas desiguales, como en $D$. jussiaei y $A$. magellanicum (Fig. 12 A, Fig. 12 B, Fig. 12 C, Fig. 12 D, Fig. 12 E, Fig. 12 F), o por muros de altura variable, anastomosantes, continuos, que delimitan aréolas regulares o irregulares, cuyo diámetro y tamaño varían en las especies. El retículo proximal puede ser completo, como en D. thyoides (Fig. 12 G) y L. clavatum subsp. contiguum (Fig. $12 \mathrm{M}$ ) o incompleto como en L. clavatum subsp. clavatum (Fig. $12 \mathrm{~J}$ ); la continuidad del retículo, ya sea éste completo e incompleto, disminuye cerca de la lesura. Los muros del retículo pueden estar fenestrados, con aberturas que forman una red o malla abierta. La lesura trilete presenta brazos que llegan hasta el ecuador de la espora, crestados y sobresalientes en todas las especies excepto $D$. jussiaei, con una lesura baja, como una cicatriz y bilabiada en toda su extensión (Fig.12 A).

En esporas reticuladas el tamaño promedio es de 33-37 $\mu \mathrm{m}$ (Cuadro 3).

La variación observada en esporas reticuladas se da a continuación, con una descripción detallada de cada táxon.

\section{Lycopodium s. $l$.}

\section{Diphasium jussiaei}

(Fig. 12 A, Fig. 12 B, Fig. 12 C)

Esporas globoso-tetraédricas, triletes, anisopolares, contorno distal circular, con ornamentación muriforme. Diámetro ecuatorial de (34) 36 (37) $\pm 0.08 \mu \mathrm{m}$. Cara distal reticulada, retículo regular, con muros 1-1.5 (2) $\mu \mathrm{m}$ de altura, con aréolas amplias y grandes, 
con una extensión que va desde 8-10 hasta $12-15 \mu \mathrm{m}$, aunque se intercalan aréolas mucho más pequeñas, de 4-6 $\mu \mathrm{m}$, de diámetro. Cíngulo ecuatorial festoneado. Cara proximal rugada o rugulada ocasionalmente con muros dispersos e interrumpidos que no forman un patrón definido, con microgránulos y orbículas. Lesura de labios angostos definidos, que no llega hasta el ecuador, sin ornamentación, bilabiada, situada en una especie de canal o ranura poco profunda de (16) $18(20) \pm 1.23 \mu \mathrm{m}$.

\section{Austrolycopodium magellanicum}

(Fig. 12 D, Fig. 12 E, Fig. 12 F).

Esporas globoso-tetraédricas, triletes, anisopolares, de contorno subcircular a subtriangular con lados curvos y ángulos redondeados, con ornamentación muriforme. Diámetro ecuatorial de (33) $34(36) \pm 1.05 \mu \mathrm{m}$. Cara distal reticulada, retículo irregular, con muros de 1-1.3 (2) $\mu \mathrm{m}$ de espesor, anastomosantes y libres hacia el interior de las aréolas, con paredes continuas o fenestradas y ruguladas; aréolas de hasta $6-7 \mu \mathrm{m}$ de diámetro con la superficie irregularmente fenestrada o perforada y con orbículas; retículo incompleto en el cíngulo ecuatorial, con muros irregularmente anastomosantes o muros parciales y estelas, que pasa parcialmente a la cara proximal. Cara proximal rugado-verrugosa, con orbículas densamente distribuidas cerca de la lesura. Lesura prominente crestada, angosta, que se extiende hasta el borde del retículo de (17) 19 (21) $\pm 1.11 \mu \mathrm{m}$.

\section{Diphasiastrum thyoides}

(Fig. 12 G, Fig. 12 H, Fig. 12 I)

Esporas globoso-tetraédricas, anisopolares, contorno circular, con ornamentación muriforme. Diámetro ecuatorial de (35) 35 (37) $\pm 1.19 \mu \mathrm{m}$. Reticuladas en la cara distal y proximal. Retículo distal regular, con aréolas

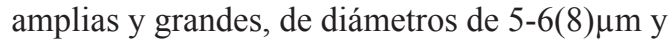
superficie con microgránulos y micropliegues; muros del retículo de 3-4 (5) $\mu \mathrm{m}$ de altura. Retículo proximal irregular, con muros que forman aréolas grandes subrectangulares, disminuye hacia la lesura y deja una zona libre de retículo, rugulada cerca de ésta; superficie de la cara proximal con microgránulos. Lesura crestada con labios angostos definidos, sin llegar hasta el ecuador, con la superficie rugulado-rugada, los bordes granulares a micropapilosos de (13) $16(18) \pm 1.36 \mu \mathrm{m}$.

\section{Lycopodium clavatum subsp. clavatum} (Fig. 12 J, Fig. 12 K, Fig 12 L)

Esporas globoso-tetraédricas, anisopolares, contorno circular, con ornamentación muriforme. Diámetro ecuatorial de (31) 33 (35) $\pm 1.38 \mu \mathrm{m}$. Reticuladas en ambas caras. Retículo distal regular formando aréolas con escasa variación en el tamaño de una espora a otra, aunque pueden variar ligeramente en la misma espora, de 2-4 hasta 5-6 $\mu \mathrm{m}$ de diámetro y con micro-ornamentación granular, dispersa en la superficie; muros relativamente uniformes en tamaño y espesor, de 2-4 (6) $\mu \mathrm{m}$ de altura, fenestrados, con amplias aberturas irregulares en sus paredes, con micro-ornamentación granular densa en los bordes. Retículo proximal completo a incompleto, con ornamentación irregular y muros no siempre anastomosantes cerca de la lesura. Lesura prominente, con forma de cresta angosta y elevada, labios finos de textura esponjosa, superficie granular, de $1.5-2.5 \mu \mathrm{m}$ de altura que se extienden casi hasta el margen ecuatorial de (11) 12 (14) $\pm 0.95 \mu \mathrm{m}$.

\section{Lycopodium clavatum subsp. contiguum} (Fig. 12 M, Fig. 12 N, Fig. 12 O)

Esporas globoso-tetraédricas, anisopolares, contorno circular, con ornamentación muriforme y reticuladas en ambas caras. Diámetro ecuatorial de (33) 37 (39) $\pm 1.20 \mu \mathrm{m}$. Retículo distal regular, aréolas con escasa variación en el tamaño de una espora a otra, aunque pueden variar algo en la misma espora, de 2-4 hasta 5-6 $\mu \mathrm{m}$ de diámetro, con microornamentación granular y microverrugas en la superficie; muros del retículo relativamente uniformes en tamaño y espesor, de 2-4 (6) $\mu \mathrm{m}$ 
de altura, marcadamente fenestrados con aberturas amplias que dejan las paredes reducidas a una malla o red; borde de los muros rugulado o granular, con gránulos y microverrugas en el borde de los muros. Retículo proximal irregular con muros incompletos altos mezclados con estelas lisas o claviformes, éstas más frecuentes cerca de la lesura. Lesura prominente, con forma de cresta angosta y elevada, labios finos, de $1.5-2.5 \mu \mathrm{m}$ de altura, ornamentados con estelas irregulares, que se extienden casi hasta el margen ecuatorial de (15) 19 (23) $\pm 2.20 \mu \mathrm{m}$.

\section{DISCUSIÓN}

Los esporocitos y la esporogénesis, la ontogenia del esporodermo y el desarrollo de las esporas hasta su maduración, así como la ornamentación característica de la pared esporal madura se han estudiado por primera vez para un número comparativamente amplio de táxones colombianos y neotropicales de Lycopodiaceae.

La cubierta de los esporocitos es una capa expansible que se deposita sobre las células madres de las esporas de pteridófitos en general y está formada principalmente por componentes de pared primaria, rica en polisacáridos carboxilados y ácidos pécticos (Pettitt \& Jermy, 1974; Sersic, 1983; Uehara \& Kurita, 1991; Rincón et al. en prep.). Heslop-Harrison (1966) y Brown \& Lemmon (2013) destacan su función de aislar las células meióticas de las vegetativas, un prerrequisito fundamental para que la esporogénesis siga un curso normal. Esto se ha observado también en todos los táxones aquí revisados; los esporocitos invierten gran parte de su actividad metabólica en la producción de esa cubierta, que es mantenida como tal hasta que tiene lugar la maduración y liberación de las esporas en la cavidad esporangial, observaciones también efectuadas por Sersic (1983) en Huperzia saururus (Lam.) Trevis.; Uehara \& Kurita (1991) en L. clavatum y Rincón et al. (2009) en H. brevifolia. Esta característica de la cubierta de los esporocitos de Lycopodiaceae coincide con las de pteridófitos, briófitos y espermatófitos, en todos los casos, la función es la protección de las células diploides que van a experimentar meiosis.

Los esporocitos inmaduros desarrollan abundantes dictiosomas, algo observado también por Lugardon (1971), Pettitt (1979), Uehara \& Kurita $(1986,1989,1991)$ y Uehara, Kurita, Sahashi \& Ohmoto (1991), quienes relacionaron este orgánulo con la formación de la cubierta de los esporocitos, opinión que se comparte aquí. Se detectaron diferencias de electro-densidad en las capas que forman esa cubierta en todos los táxones estudiados, que se atribuyen a diferencias en la composición química.

En el citoplasma de los esporocitos inmaduros son escasos los depósitos lipídicos, especialmente en comparación con etapas posteriores, como esporocitos premeióticos, tétradas y esporas, en donde estas reservas son abundantes. Una condición similar se observó también en otros licopodios (Sersic, 1983; Lugardon, 1990; Uehara \& Kurita, 1991; Rincón et al., 2009; Rincón et al. en prep.) y coincidiría con su utilización como aporte energético hasta que las esporas germinan y se forman los gametófitos (Gullvag, 1969; Gemmrich, 1977; Randi \& Felippe, 1988; Raghavan, 1989; Ballesteros \& Walters, 2007; Rincón et al., 2009; Ballesteros 2011; Gabriel \& Galán y Prada, 2011).

Uehara \& Kurita (1991) estudiaron la ontogenia del esporodermo en L. clavatum y señalaron que la formación del exosporio externo (responsable de la macro-ornamentación de las esporas) se inicia inmediatamente después de terminar la meiosis, durante la etapa de tétrada, como también sucede en Psilotum Sw. y Ophioglossum L. (Pettitt, 1979; Schraudolf, 1984; Uehara \& Kurita, 1986, 1989; Lugardon, 1990). Uehara \& Kurita (1991) observaron en L. clavatum ondulaciones y pliegues en la membrana de las esporas inmaduras, los asociaron con acumulación de material electrodenso y concluyeron que los patrones de ornamentación de las esporas están determinados por la posición de la membrana celular sin la participación de microtúbulos. Las observaciones realizadas aquí discrepan con lo antes 
mencionado ya que los patrones de ondulación y plegamiento de la membrana son evidentes desde etapas tempranas de la esporogénesis en esporocitos premeióticos, y en este sentido, resalta la importancia de los esporocitos y su componente diploide en la determinación de los patrones de ornamentación de las esporas en Lycopodiaceae. La importancia del componente diploide en la determinación de la ornamentación de las esporas también ha sido descrita en algunas hepáticas (Brown, Lemmon, \& Renzaglia, 1986). La presencia de microtúbulos asociados con la cara distal de las esporas en P. cernua durante el depósito del esporodermo, podría implicar la participación de este orgánulo en la formación de los patrones de ornamentación de las esporas. Es posible que los abundantes depósitos lipídicos en los esporocitos y esporas de Lycopodiaceae dificulten la visualización de estos orgánulos celulares y por consiguiente podrían interferir con la correcta interpretación de estos eventos.

Los plastidios y zonas perinucleares actúan como centros de organización de microtúbulos y coordinan la mitosis y la meiosis en plantas (Pickett-Heaps, 1969; Brown \& Lemmon, 2013). En el modelo monoplastidial, un solo plastidio que se divide dos veces forma un sistema cuadripolar de microtúbulos en el cenocito tetranucleado, que es el resultado final de la división celular y esta condición se ha considerado plesiomórfica, originada en los ancestros algales (Brown \& Lemmon, 1990 a, 1997, 2001 a, b, 2013). En el modelo poliplastidial hay varios plastidios pero son ciertas áreas perinucleares difusas del citoplasma las que actúan como centros de organización de microtúbulos (Brown \& Lemon 2001 a, b, 2013). El modelo monoplastidial está difundido en briófitos, con excepción de algunas hepáticas y Megaceros Campbell (Brown \& Lemmon, 2013), es raro en plantas vasculares y sólo se ha observado en la mitosis y meiosis de licófitos heterospóricos como Selaginella Pal. Beauv. e Isoetes L. (Brown \& Lemmon, 1985, 1989, 1991; Cleary, Brown, \& Lemmon, 1992), en licófitos homospóricos como L. clavatum (Uehara \& Kurita, 1991), y aquí, en D. thyoides; esta podría ser la condición más común al menos en Lycopodium s. l.. Por otra parte, la condición poliplastidial es dominante en monilófitos (con la excepción del helecho maratiáceo Angiopteris Hoffman) y espermatófitos (Brown \& Lemon, 1990 a, 1997, 2001 a, b, 2013), y esta condición se observó en algunos licófitos homospóricos de los géneros Huperzia y Lycopodiella s. l. como $H$. brevifolia, H. tetragona y P. cernua. Si se acepta que la condición poliplastidial es derivada (Brown \& Lemon, 2001a, b) podría haber surgido de manera independiente en táxones de Huperzia y Lycopodiella s.l., dado que este último grupo está más relacionado con Lycopodium s. l. (Wikström \& Kenrick, 2000 b, 2001). Sin embargo, para corroborar esta hipótesis se requeriría estudiar un mayor número de táxones de la familia (incluyendo Phylloglossum por su afinidad con Huperzia), ya que hasta este momento sólo se conocía la condición monoplastidial descrita para L. clavatum.

El tapete de Lycopodiaceae es celular y de tipo secretor (Rolleri, 1972 a; Sersic, 1983; Uehara \& Kurita, 1991; Rincón et al., 2009; Rincón et al., en prep.). Aquí se concluye que en la especie monoplastidial $D$. thyoides el tapete secreta de manera activa vesículas cargadas de material de composición y electro densidad similares a las del exosporio externo, lo que podría indicar que se encuentran formadas por esporopolenina o sus precursores (cuerpos lipídicos). El tapete descarga estas vesículas en la cavidad esporangial y son dirigidas hacia las tétradas en formación. La abundancia de cuerpos plurivesiculares en el citoplasma de las células del tapete es evidencia de su alta actividad metabólica y secretora. En las especies poliplastidiales examinadas, $H$. brevifolia, $H$. tetragona y $P$. cernua, se encontraron corpúsculos de esporopolenina próximos al tapete y en la cavidad esporangial hacia el final de la esporogénesis, lo que sugiere una actividad secretora del tapete menos intensa en comparación con D. thyoides. En P. cernua los restos del tapete forman un material granular electro denso muy fino que se deposita sobre el exosporio externo al final de la esporogénesis y da origen al perisporio. Este está constituido 
por dos capas que se distinguen por sus propiedades de electro-densidad: una externa de material menos electro-denso y una interna más electro densa en contacto directo con el exosporio externo. Tryon \& Lugardon (1991) efectuaron observaciones similares en Lycopodiella s.l. y Phylloglossum, aunque en este último género el perisporio consta de una sola capa de material electro-denso.

En todos los táxones aquí estudiados, la formación del esporodermo es centrípeta y se inicia con el depósito del exosporio externo; posteriormente, se depositan el exosporio interno y endosporio, y al final, si está presente, el perisporio. Estas observaciones coinciden de manera general con trabajos previos (Afzelius, Erdtman, \& Sjöstrand, 1954; Lugargon, 1990; Tryon \& Lugardon, 1991; Uehara \& Kurita, 1991, Rincón et al., en prep.) y aunque en términos de desarrollo y composición química son similares al esporodermo de licófitos heterospóricos, difieren ampliamente en estructura (Tryon \& Lugardon, 1991; Uehara, Kurita, Sahashi \& Ohmoto, 1991; Morbelli, 1995; Wellmann, 2004). El depósito del exosporio externo en Lycopodiaceae inicia con la formación de una capa trilaminar constituida por materiales de diferente electro-densidad, que ha sido designada "white line centered lamellae" o WLCL (Blackmore \& Barnes, 1987). Esta capa trilaminar se deposita sobre la membrana celular de las esporas al final de la meiosis. Los detalles ultraestructurales sobre la forma en que se deposita el exosporio externo en Lycopodiaceae son importantes porque refuerzan la idea que la presencia de esta capa trilaminar sería un carácter plesiomórfico y homólogo en todos los grupos de plantas, ya que se ha observado en briófitos (Brown \& Lemmon, 1990 b), pteridófitos (Lugardon, 1990; Tryon \& Lugardon, 1991) espermatófitos (Blackmore, Wortley, Skvarla, \& Rowley, 2007; Wallace, Fleming, Wellman, \& Beerling, 2011) y en Chlorella Beijerinck (Atkinson, Gunninga, \& John, 1972).

Blackmore \& Barnes (1987) describen cuatro patrones de depósito de esporopolenina en el exosporio externo, tres de los cuales incluyen la formación de WLCL y uno caracterizado por la reducción o pérdida secundaria de esta estructura en algunos táxones. Esos autores consideran que en briófitos y pteridófitos se forma WLCL sobre la membrana celular y sobre esta capa se depositan otras trilaminares hasta formar una estructura multilaminar que se torna homogénea con la maduración de las esporas. El tapete agregaría capas adicionales o formaría orbículas que pueden formar parte del esporodermo o no. Este modelo explica con mayor exactitud la manera en que se forma el exosporio en las Lycopodiaceae aquí estudiadas. De acuerdo con las observaciones, se considera que los patrones de ondulación y plegamiento de la membrana de los esporocitos, asociados con depósitos electro densos, podrían estar indicando, además, los sitios en los cuales el WLCL inicia su formación una vez terminada la meiosis.

En las esporas maduras de los táxones aquí analizados se encontraron dos patrones principales de ornamentación: caviforme y muriforme; este último con dos subtipos: rugado, con muros típicos no anastomosantes y reticulado. Los tipos hallados coinciden con los patrones de ornamentación descritos y propuestos por Wilce (1972) y Kongoi et al. (2007), aunque los términos utilizados aquí para la descripción fueron tomados de Lellinger (2002). Otros trabajos sobre esporas de Lycopodiaceae de Colombia como los de Solé de Porta \& Murillo-Pulido (2005) y Contreras et al. (2006) coinciden también con los tipos principales de ornamentación y las especies que se agrupan en ellos, con escasas excepciones: Contreras et al. (2006) describen las esporas de H. tenuis como foveoladas (aquí se ilustran como rugadas), y Solé de Porta \& Murillo-Pulido (2005) y Tryon \& Lugardon (1991) describen las de H. molongensis como fosuladas (aquí se han visto que son foveoladas y que estas foveolas se unen cerca al ecuador formando fósulas).

Las esporas con ornamentación caviforme negativa, foveoladas, son características de las especies de Huperzia que crecen como terrestres, saxícolas, rupícolas, o de pajonales de altura, aunque también se presentan en especies 
epífitas, erguidas o péndulas. Las esporas con ornamentación muriforme, rugadas, con muros gruesos no anastomosantes aparecen en $H$. curvifolia, $H$. dichotoma y $H$. tenuis, y son más comunes o características de especies de Lycopodiella, Palhinhaea y Pseudolycopodie$l l a$, mientras que las reticuladas se encuentran solamente en especies terrestres de Austrolycopodium, Diphasium, Diphasiastrum y Lycopodium. Las mediciones efectuadas en esporas foveoladas y rugadas sugieren una variación similar en especies terrestres de diversos hábitats y epífitas, sin una relación evidente con el hábito y/o hábitat. Las esporas de mayor tamaño se presentaron en $L$. andicola y $P$. glaucescens. En esporas reticuladas el rango promedio de tamaño es el menor de todos los táxones estudiados y serían las esporas más pequeñas de la familia.

Los tipos de ornamentación, la distribución de los canales de mucílago, la morfología del esporangio, los gametófitos y aspectos fitoquímicos, entre otros, fueron la base de la división de la familia Lycopodiaceae en cuatro géneros: Huperzia, Lycopodium, Lycopodiella y Phylloglossum (Øllgaard, 1987).

Los patrones de la macro-ornamentación hallados sugieren tres grandes grupos de afinidad: las especies reunidas en el género Huperzia con ejes sin diferenciación en estróbilos típicos y hábito terrestre o epífítico que se caracterizan por las esporas foveoladas con superficie lisa y ocasionalmente, ornamentación que combina fovéolas típicas con superficie algo rugulada; las especies terrestres agrupadas sub Lycopodiella s. l. (incluyendo Lycopodiella s. str., Pseudolycopodiella y Palhinhaea), con ejes diferenciados y estróbilos péndulos, unas pocas especies epífitas de Huperzia con áreas estrobilares péndulas, que presentan esporas rugadas y finalmente, las especies con marcada diferenciación de los ejes, estróbilos típicos, esporofilos modificados diferentes de los trofofilos y de hábito terrestre y rizomatoso (Austrolycopodium, Diphasiastrum, Diphasium y Lycopodium) se caracterizan por las esporas reticuladas.
Los patrones de ornamentación de Huperzia y Phlegmariurus son muy similares. Phlegmariurus fue segregado de Huperzia por Holub (1964) y su separación adoptada por Wagner \& Beitel (1992, 1993) y por Øllgaard (2012 a, b). Los caracteres utilizados para separarlos son la presencia de yemas vegetativas y esporas con lados cóncavos en el ecuador y ángulos truncados en especies de Huperzia versus la ausencia de yemas y las esporas con lados convexos o más o menos planos en el ecuador y ángulos obtusos o agudos en Phlegmariurus. Los caracteres de las esporas coinciden con dos de los tipos propuestos por Wilce (1972) para esporas foveolado-fosuladas: tipo Selago y tipo Phlegmaria. Devi \& Singh (2011) consideraron que ambos tipos deben tratarse como uno solo dadas sus semejanzas ultraestructurales. En relación con las yemas, Kongoi et al. (2007) las hallaron en todas las especies terrestres de Huperzia analizadas por ellos, y asumieron que la presencia y cantidad de yemas dependería de cada especie en particular ante factores ecológicos. La biología molecular parecería indicar que la separación es innecesaria y sugiere que Huperzia es el origen de Phlegmariurus (Ji, Hou, Wang, \& Pan, 2008).

Las especies con esporas foveoladas están indudablemente relacionadas y es posible que exista una cierta continuidad en los patrones de ornamentación desde tipos foveolados a foveolado-fosulados y también a rugados, y que ese modelo evolutivo sea antiguo en el grupo ya que no parece estar relacionado con aspectos ecológicos o hábito. Dentro de la uniformidad aparente del patrón foveolado se ha visto que varían, en el nivel específico, rasgos como el diámetro, la densidad $\mathrm{y}$, en algunos casos, el grado de fusión de las fovéolas (fósulas), el tamaño de las esporas, su diámetro ecuatorial y el tipo de lesura, que puede ser fina y delgada, plana, sobresaliente, moderadamente crestada, entre otras. En esporas rugadas, varían en el nivel específico el tipo, altura, proximidad o distancia, continuidad y micro-ornamentación de los muros, presencia o ausencia de muros en la cara proximal, la ornamentación o micro-ornamentación de la cara proximal y 
los caracteres de la lesura (baja, sobre elevada, labiada, crestada, etc.).

En esporas reticuladas, las variaciones que se registran en el nivel específico se refieren a la altura, superficie, presencia o ausencia de fenestraciones y de micro-ornamentación de los muros, contorno, superficie y presencia o ausencia de micro-ornamentación de las areolas, presencia o ausencia de retículo proximal y tipos de lesura. La condición reticulada se ha considerado un carácter sinapomórfico en Lycopodium (Wikström, 2001) pero los táxones aquí revisados no son suficientes para proponer una relación de origen con patrones que presentan muros menos elaborados morfológicamente. En especies paleotropicales, menos estudiadas, podrían hallarse variaciones diagnósticas en el nivel específico como las señaladas para las neotropicales u otras. Por ejemplo, Lycopodium deuterodensum Herter presenta una ornamentación formada por estelas cortas y delgadas con ápice obtuso o redondeado, que derivaría del tipo reticulado (Wikström \& Kenrick (2001)), y otra especie paleotropical, Lycopodium casuarinoides Spring tiene esporas cuya ornamentación ha sido diversamente interpretada e ilustrada: Wilce (1972) las llamó escabradas, un término que significa áspero, pero ilustró esporas triletes psiladas con orbículas dispuestas con densidad variable, que no mencionó; Tryon \& Lugardon (1991) ilustraron esporas similares pero las incluyeron entre las reticuladas y mencionaron la existencia de glóbulos (orbículas); más recientemente, Kongoi et al. (2007) describieron las esporas de esa especie como reticuladas, observaron que el exosporio es reticulado y presentan perisporio, lo que podría explicar la capa lisa y con orbículas que ilustran autores previos. Las ilustraciones de Kongoi et al. (2007) muestran una gran similitud de las esporas de L. casuarinoides con las de D. thyoides. Es muy posible que el modelo reticulado haya derivado como una modificación de tipos rugados y también que la fragmentación de los muros más o menos discontinuos haya dado lugar a otros tipos esteliformes (por ejemplo, el modelo de L. deuterodensum), también derivados, pero por el momento esto es sólo una hipótesis que se requiere analizar más detalladamente en Lycopodiaceae.

De acuerdo con lo observado en la morfología esporal hasta el momento, los tipos de ornamentación no coinciden con la extrema fragmentación en varios géneros (Holub, 1964, 1975, 1983, 1985, 1991; Wagner \& Beitel, 1992, 1993; Øllgaard 2012 a, b), aunque podría coincidir, a priori, con la idea de tres subfamilias (Wagner \& Beitel, 1992, 1993). Los autores consideran que para entender de forma clara y precisa las relaciones taxonómicas y sistemáticas dentro de la familia se requiere del conocimiento y la utilización de un conjunto de caracteres diagnósticos provenientes de la morfología del esporófito, de las esporas y comprensión de la citología. Si se tiene en cuenta que muchas especies se siguen describiendo en la actualidad sobre la base de rasgos escasos, a veces someros, y que con frecuencia es difícil distinguir algunos táxones morfológicamente similares a causa de la intrínseca plasticidad del grupo, los caracteres diagnósticos específicos de la ornamentación esporal podrían incorporarse en futuras descripciones para su mejor reconocimiento y con el fin de delimitar adecuadamente a las especies.

\section{AGRADECIMIENTOS}

Los autores agradecen a las siguientes instituciones y personas: Instituto de Biología de la Universidad de Antioquia (UdeA-Laboratorio de Botánica), Departamento de Biología Universidad del Valle (UNIVALLE-Sección Botánica), Unidad de Microscopía Electrónica de la Universidad del Cauca (UNICAUCA), a Sayonara Plata (UdeA) por su colaboración en la edición fotográfica y Natalia Pabón Mora (UdeA) por sus oportunos y acertados comentarios. Este estudio forma parte de una serie de trabajos que integran la Tesis Doctoral del primer autor, quien agradece también a Benjamin Øllgaard (Universidad de Aarhus, Dinamarca) por su valiosa ayuda en la identificación de algunos especímenes y suministro de material bibliográfico. 


\section{RESUMEN}

Estudios sobre aspectos reproductivos, morfología y ultraestructura de las esporas de Lycopodiaceae no son abundantes en la literatura científica y constituyen información esencial para apoyar las relaciones taxonómicas y sistemáticas en el grupo. Con el fin de completar la información existente, añadiendo contribuciones nuevas y más amplias sobre estos temas, se realizó un análisis comparado de la ultraestructura de la esporogénesis, con énfasis en aspectos citológicos que tienen que ver con la formación de la cubierta de los esporocitos, el tapete, las meiosis monoplastidial y poliplastidial, la ontogenia del esporodermo y la ornamentación de las esporas maduras en 43 táxones de ocho géneros de Lycopodiaceae: Austrolycopodium, Diphasium, Diphasiastrum, Huperzia (incluyendo Phlegmariurus), Lycopodium, Lycopodiella, Palhinhaea y Pseudolycopodiella que crecen en los Andes de Colombia y el Neotrópico. Para estudios con microscopía electrónica de trasmisión (MET) las muestras se recolectaron en los departamentos de Cauca y Valle del Cauca, mientras que la mayoría de las muestras para microscopía electrónica de barrido (MEB) provienen de material herborizado de colecciones. Para la observación de las muestras con MET y MEB se utilizaron protocolos estándar para el procesamiento de esporas. La cubierta de los esporocitos está formada por pared primaria; los esporocitos invierten gran parte de su actividad metabólica en la producción de esa cubierta, que es mantenida hasta la liberación de las esporas y tiene funciones de protección de las células que harán meiosis. La abundancia de dictiosomas en los esporocitos se relacionó con la formación y desarrollo de la cubierta. Además de la actividad de los microtúbulos, la presencia de sinuosidades y plegamientos asociados con material electro denso en la membrana de los esporocitos determinarían tempranamente los patrones de ornamentación de las esporas. La condición monoplastidial es común en Lycopodium s.l.y la poliplastidial se observó en Huperzia y Lycopodiella $s$. $l$. En especies monoplastidiales el tapete presenta abundantes cuerpos plurivesiculares, en las poliplastidiales la actividad secretora del tapete es menos intensa. El desarrollo del esporodermo es centrípeto, el exosporio se forma primero, seguido del endosporio y el perisporio, si está presente, se deposita de último. En las esporas adultas de Lycopodiaceae se encontraron dos patrones de ornamentación: negativo o caviforme (esporas foveoladas) y positivo o muriforme (esporas rugadas y reticuladas). Las esporas foveoladas son características de Huperzia; las rugadas de unas pocas especies de Huperzia y las especies de Lycopodiella s. $l$., mientras que las reticulada son típicas de Lycopodium s. l.. Numerosos caracteres de la ornamentación resultan diagnósticos en el nivel específico. Los tipos principales no apoyan la extrema fragmentación reciente de la familia en varios géneros, aunque podría coincidir, a priori, con la idea de tres subfamilias. Los hallazgos de la esporogénesis, extremadamente similar en todos los táxones estudiados, apuntan más a la unificación de los géneros en la familia que a su segregación.
Palabras clave: esporodermo, esporogénesis, Lycopodiaceae, ornamentación de las esporas, ontogenia del esporangio, ultraestructura.

\section{REFERENCIAS}

Afzelius, B. M., Erdtman, G., \& Sjöstrand, F. S. (1954). On the fine structure of the outer part of the spore wall of Lycopodium clavatum as revealed by the electron microscope. Svensk Botanisk Tidskrift, 48, 155-161.

Ambrose, B. A. (2013). The morphology and development of Lycophytes. In B. A. Ambrose \& E. M. Purugganan (Eds.), Annual plant reviews volume 45. The Evolution of Plant Form (pp. 91-110). Oxford, England: John Wiley \& Sons.

Arana, M. D. \& Øllgaard, B. (2012). Revisión de las Lycopodiaceae (Embryopsida, Lycopodiidae) de Argentina y Uruguay. Darwiniana, 50(2), 266-295.

Atkinson, A. W., Gunninga, B. E. S., \& John, P. C. L. (1972). Sporopollenin in the cell wall of Chlorella and other algae: Ultrastructure, chemistry and incorporation of $14 \mathrm{C}$-Acetate studied in synchronous culture. Planta, 107, 1-32.

Ballesteros, D. (2011). Conservation of fern spores. In H. Fernandez, A. Kumar, \& M. A. Revilla (Eds.), Working with ferns issues and applications (pp. 165-172). New York, U.S.A: Springer.

Ballesteros, D. \& Walters, C. (2007). Calorimetric properties of water and triacylglycerols in fern spores relating to storage at cryogenic temperatures. Cryobiology, 55, 1-9.

Blackmore, S. \& Barnes, S. H. (1987). Embryophyte spore walls: origins, development, and homologies. Cladistics, 3(2), 185-195.

Blackmore, S., Wortley, A. H., Skvarla, J. J., \& Rowley, J. R. (2007). Pollen wall development in flowering. New Phytologist, 3, 483-498.

Brown, R. C. \& Lemmon, B. E. (1985). Development of stomata in Selaginella: division polarity and plastid movements. American Journal Botany, 72, 1914-1925.

Brown, R. C., \& Lemmon, B. E. (1989). Morphogenetic plastid migration and microtubule organization during megasporogenesis in Isoetes. Protoplasma, 152, 136-147.

Brown, R. C. \& Lemmon, B. E. (1990 a). Monoplastidic cell division in lower land plants. American Journal Botany, 77, 559-571.

Brown, R. C. \& Lemmon, B. E. (1990 b). Sporogenesis in bryophytes. En S. Blackmore \& R. B. Knox (Eds.), Microspores: evolution and ontogeny (pp. 55-94). London, England: Academic Press. 
Brown, R. C. \& Lemmon, B. E. (1991). Plastid polarity and meiotic spindle development in microsporogenesis of Selaginella. Protoplasma, 161, 168-180.

Brown, R. C. \& Lemmon, B. E. (1997). The quadripolar microtubule system in lower land plants. Journal of Plant Research, 110, 93-106.

Brown, R. C. \& Lemmon, B. E. (2001a). Sporogenesis in Eusporangiate Ferns: II. Polyplastidic Meiosis in Ophioglossum (Ophioglossales). Journal of Plant Research, 114, 237-246.

Brown, R. C. \& Lemmon, B. E. (2001b). Sporogenesis in Eusporangiate Ferns: 1. Monoplastidic Meiosis in Angiopteris (Marattiales). Journal of Plant Research, 114, 223-235.

Brown, R. C. \& Lemmon, B. E. (2013). Sporogenesis in Bryophytes: patterns and diversity in meiosis. The Botanical Review, 79, 178-280.

Brown, R. C., Lemmon, B. E., \& Renzaglia, K. (1986). Sporocytic control of spore wall pattern in liverworts. American Journal of Botany, 73(4), 593-596.

Cleary, A. L., Brown, R. C., \& Lemmon, B. E. (1992). Microtubule arrays during mitosis in monoplastidic root tip cells of Isoetes. Protoplasma, 167, 123-133.

Contreras, D. A. R., Bogotá, A. R. G., \& Jiménez, B. L. C. (2006). Atlas de las esporas de pteridófitos de Chipaque (Cundinamarca, Colombia). Caldasia, 28(2), 327-357.

Devi, Y. S. \& Singh, P. K. (2011). Additional notes on spore morphology of two Huperzia (Lycopodiaceae) species and systematic significance. Research Journal of Botany, 6(2), 78-86.

DiMichele, W. A. \& Skog, J. R. (1992). The Lycopsida: A Symposium. Annals of the Missouri Botanical Garden, 73(3), 447-449.

Gabriel y Galán, J. M. \& Prada, C. (2011). Pteridophyte spores viability. In H. Fernandez, A. S. Kumar, \& M. A. Revilla (Eds.), Working with ferns issues and applications (pp.193-205). New York, U.S.A: Springer.

Gemmrich, A. R. (1977). Fatty acid composition of fern spore lipids. Phytochemistry, 16(7), 1044-1046.

Gullvag, B. M. (1969). Primary storage products of some pteridophyte spores - a fine structural study. Phytomorphology, 19, 82-92.

Haines, A. (2003). The families Huperziaceae and Lycopodiaceae in New England. Bowdoin, U.S.A: V.F. Thomas Co.

Herter, W. (1950) Systema Lycopodiorum. Revista Sudamericana de Botanica, 8(4), 93-116.

Heslop-Harrison, J. (1966). Cytoplasmic continuities during spore formation in flowering plants. Endeavour, $25,65-72$.
Holub, J. (1964). Lycopodiella, novy rod radu Lycopodiales. Preslia, 36, 16-22.

Holub, J. (1975). Diphasiastrum, a new genus in Lycopodiaceae. Preslia, 47, 97-110.

Holub, J. (1983). Validation of generic names in Lycopodiaceae: with a description of a new genus Pseudolycopodiella. Folia Geobotanica \& Phytotaxonomica, 18, 439-442.

Holub, J. (1985). Transfer of Lycopodium species to Huperzia with a note on generic classification in Huperziaceae. Folia Geobotanica \& Phytotaxonomica, 20, 67-80.

Holub, J. (1991). Some taxonomic changes within Lycopodiales. Folia Geobotanica \& Phytotaxonomica, 26, 81-94.

Ji, S. G., Hou, K. K., Wang, J., \& Pan, S. L. (2008). A molecular phylogenetic study of Huperziaceae based on chloroplast $r b c L$ and $p s b A$-trnH sequences. Journal of Systematics and Evolution, 46(2), 213-219.

Kenrick, P. \& Crane, P. R. (1997). The origin and early diversification of land plants: A cladistic study. Washington, U.S.A: Smithsonian Institution Press.

Knox, E. M. (1950). The spores of Lycopodium, Phylloglossum, Selaginella and Isoetes and their value in the study of microfossils of Paleozoic age. Transactions and Proceedings of the Botanical Society of Edinburgh, 35, 211-317.

Kongoi, C., Go, R., Pungga, R. S., \& Kader, H. M. (2007). Variations in spore and sporangium surface structure of the fern-allies Lycopodiaceae P. Beauv. ex Mirbel in Malaysia. Journal Biosains, 18(2), 77-97.

Lellinger, D. B. (2002). A modern multilingual glossary for taxonomic pteridology. Pteridologia, 3, 1-263.

Lellinger, D. B. \& Taylor, W. C. (1997). A classification of spore ornamentation in the Pteridophyta. In J. M. Camus, M. Gibby, \& R. J. Johns (Eds.), Pteridology in perspective (pp. 33-42). Kew, England: Royal Botanic Gardens.

Lugardon, B. (1971). Contribution a la connaissance de la morphogenèse et de la structure des parois sporales chez les Filicinées isosporées. These, University P. Sabatier. Toulouse.

Lugardon, B. (1990). Pteridophyte sporogenesis: a survey of spore wall ontogeny and fine structure in a polyphyletic plant group. In S. Blackmore \& R. B. Knox (Eds.), Microspores: evolution and ontogeny (pp. 95-120). London, England: Academic Press.

Morbelli, M. A. (1995). Megaspore wall in Lycophytaultrastructure and function. Review of Palaeobotany and Palynology, 85, 1-12.

Murillo, M. T. \& Harker, M. (1990). Helechos y plantas afines de Colombia. Bogotá, Colombia: Academia 
Colombiana de Ciencias Exactas, Físicas y Naturales. Colección Jorge Álvarez Lleras. 12.

Murillo, M. T. \& Murillo, J. (1999). Pteridófitos de Colombia I. Composición y distribución de las Lycopodiaceae. Academia Colombiana de Ciencias Exactas, Físicas y Naturales, 23(86), 19-38.

Murillo, M. T., Murillo, J., León, A., \& Triana, L. A. (2008). Los pteridófitos de Colombia. Bogotá, Colombia: Instituto de Ciencias Naturales, Facultad de Ciencias, Universidad Nacional de Colombia. Biblioteca José Jerónimo Triana $\mathrm{N}^{\circ} 18$.

Øllgaard, B. (1975). Studies in Lycopodiaceae, I. Observations on the structure of the sporangium wall. American Fern Journal, 65(1), 19-27.

Øllgaard, B. (1987). A revised classification of the Lycopodiaceae s. lat. Opera Botanica, 92, 153-178.

Øllgaard, B. (1988). Lycopodiaceae. In G. Harling \& L. Andersson (Eds.), Flora of Ecuador (Vol. 33, 1-156). Quito, Ecuador: Arlöv Berlings.

Øllgaard, B. (1990). Lycopodiaceae. In K. Kubitzki (Ed.), The Families and genera of vascular plants (Vol. 1, 31-39). Berlin, Germany: Springer.

Øllgaard, B. (1992). Neotropical Lycopodiaceae-an overview. Annals of the Missouri Botanical Garden, 79(3), 687-717.

Øllgaard, B. (1996). Neotropical Huperzia (Lycopodiaceae)distribution of species richness. In J. M. Camus., M. Gibby \& R. J. Johns (Eds.), Pteridology in perspective (pp. 93-100). London, England: Royal Botanical Gardens.

Øllgaard, B. (2012a). Nomenclatural changes in Brazilian Lycopodiaceae. Rodriguésia, 63, 479-482.

Øllgaard, B. (2012b). New combinations in Neotropical Lycopodiaceae. Phytotaxa, 57, 10-22.

Pettitt, J. M. (1979). Ultrastructure and cytochemistry of spore wall morphogenesis. In A. F. Dyer (Ed.), The experimental biology of ferns (pp. 213-252). London, England: Academic Press, London.

Pettitt, J. M. \& Jermy, A. C. (1974). The surface coats on spores. The Biological Journal of the Linnean Society, 6(3), 245-257.

Pickett-Heaps, J. D. (1969). The evolution of the mitotic apparatus: an attempt at comparative ultrastructural cytology in dividing plant cells. Cytobios, 1, 257-280.

Pita P. B, De Menezes, N., \& Prado, J. (2006). Morfologia externa e interna das folhas vegetativas, esporofilos e esporângios de espécies de Huperzia Bernh. (Lycopodiaceae-Pteridophyta) do Brasil. Revista Brasileira de Botânica, 29(1), 115-131.

Raghavan, V. (1989). Developmental biology of fern gametophyte. Cambridge, England: Cambridge University.
Ramírez, P. B. R. \& Macías, D. P. J. (2007). Catálogo de helechos y plantas afines del departamento del Cauca. Popayán, Colombia: Universidad del Cauca.

Randi, A. M. \& Felippe, G. M. (1988). Mobilization of storage reserves during Cyathea delgadii spore germination. Journal of Plant Research, 101(4), 529-532.

Raubeson, L. A. \& Jansen, R. K. (1992). Chloroplast DNA evidence on the ancient evolutionary split in vascular land plants. Science, 255, 1697-1699.

Renzaglia, K. S., Duff. R. J., Nickrent, D. L., \& Garbary, D. J. (2000). Vegetative and reproductive innovations of early land plants; implications for a unified phylogeny. Philosophical Transactions of the Royal Society, B 355, 769-793.

Rincón, B. E. J., Gélvez, L. V., Forero, H. G., Arrieta, P. D., \& Hleap, J. S. (2009). Ontogenia del esporangio y esporogénesis del licopodio Huperzia brevifolia (Lycopodiaceae) de las altas montañas de Colombia. Revista de Biología Tropical, 57(4), 1141-1152.

Rolleri, C. H. (1972 a). Morfología comparada de las especies de "Lycopodium" (Pteridophyta-Lycopodiaceae) para el noroeste argentino. Revista del Museo de La Plata, 12, 223-317.

Rolleri, C. H. (1972 b). Sobre la presencia y naturaleza de la endodermis en especies de Lycopodium L. Boletín de la Sociedad Argentina de Botánica, 14, 365-369.

Rolleri, C. H. (1975). Acerca de los conductos glandulares en hojas de Lycopodium alopecuroides L Lycopodiaceae-Pteridophyta. Boletín de la Sociedad Argentina de Botánica, 16, 397-405.

Rolleri, C.H. (1978). Dos nuevas especies de Lycopodium L. para los Andes tropicales. Hickenia, 1, 142-148.

Rolleri, C. H. (1979). Análisis morfológico y revisión sistemática de las especies andino- patagónicas del género Lycopodium L. Lycopodiaceae-Pteridophyta. Physis, 95, 39-62.

Rolleri, C. H. (1980). Estudios morfológicos y sistemáticos en la sección Crassistachys Herter del género Lycopodium L. L. brevifolium Hook. \& Grev. y L. rufescens Hook. Boletín de la Sociedad Argentina de Botánica, 19, 243-254.

Rolleri, C. H. (1981). Sinopsis de las especies de Lycopodium L. (Lycopodiaceae Pteridophyta) de la sección Crassistachys Herter. Revista del Museo de La Plata, 12, 61-114.

Rolleri, C. H. (1982a). El número cromosómico Lycopodium saururus Lam. (Lycopodiaceae-Pteridophyta) y sus implicancias sistemáticas. Revista del Museo de La Plata, 13, 115-118.

Rolleri, C. H. (1982 b). El número cromosómico de Lycopodium clavatum L. subsp. clavatum (Lycopodiaceae-Pteridophyta) y sus implicancias sistemáticas. Revista del Museo de La Plata, 13, 119-122. 
Rolleri, C. H. (1984). Notas nomenclaturales y taxonómicas en la sección Crassistachys Herter del género Lycopodium L.: L. cruentum Spring. Revista del Museo de La Plata, 14, 45-63.

Rolleri, C. H. (1985 a). Notas nomenclaturales y taxonómicas en la sección Crassistachys Herter del género Lycopodium L., II. Revista del Museo de La Plata, 14, 1-9.

Rolleri, C. H. (1985 b). Estudios morfológicos y sistemáticos en la sección Crassistachys Herter del género Lycopodium L. Revista del Museo de La Plata, 13, 189-196.

Rolleri, C. H. \& Deferrari, A. M. (1986). Modelos epidérmicos y otros caracteres foliares en la sistemática y ecología de Lycopodium L., sección Crassistachys Herter. Revista del Museo de La Plata, 14(91), 65-79.

Rolleri, C. H., Prada, C., \& Martínez, O. G. (2010). Huperzia reflexa y Lycopodiella cernua (LycopodialesPteridophyta): dos nuevas citas para el NO de la Argentina y actualizaciones sobre su morfología. Botanica Complutensis, 34, 41-48.

Rodríguez, D. W. (2002). Helechos, Licopodios, selaginelas y equisetos del Parque Regional Arvi. Medellín, Colombia: CORANTIOQUIA.

Santa, J. 1989. Estudio sobre la distribución de algunas licopodíneas de Colombia. Actualidades Biológicas, 18, 95-103.

Schneider, H., Schuettpelz, E., Pryer, K, M., Cranfill, R., Magallón, S., \& Lupia, R. (2004). Ferns diversified in the shadow of angiosperms. Nature, 428, 553-557.

Schraudolf, H. (1984). Ultrastructural events during sporogenesis of Anemia phyllitidis (L.) Sw. II. Spore wall formation. Beitraege zur Biologie der Pflanzen, 59, 237-260.

Sersic, A. N. (1983). Ontogenia del esporangio y esporogénesis en Lycopodium saururus (Lycopodiaceae). Boletín de la Sociedad Argentina de Botánica, 22(14), 205-220.

Solé de Porta, N. \& Murillo-Pulido, M. T. (2005). Estudio palino-botánico de algunas especies de pteridophyta de Colombia. Revista de la Academia Colombiana de Ciencias Exactas, Físicas y Naturales, 29(111), 183-218.

Smith, A. R., Pryer, K. M., Schuettpelz, E., Korall, P., Schneider, H., \& Wolf, P. G. (2006). A classification for extant ferns. Taxon, 55(3), 705-731.

Tryon, A. F. \& Lugardon, B. (1991). Spores of the pteridophyta: Surface, wall structure, and diversity based on electron microscope studies $\left(1^{\text {st }} \mathrm{ed}\right.$.). New York, U.S.A: Springer.

Tryon, R. \& Tryon, A. (1982). Ferns and allied plants with special reference to tropical America ( $1^{\text {st }}$ ed.). New York, U.S.A: Springer.
Tryon, R. M. \& Stolze, R. G. (1994). Pteridophyta of Peru. Part VI. 22. Marsileaceae-21. Isoetaceae. Fieldiana Botany, 34, 1-123.

Uehara, K. \& Kurita, S. (1986). Ultrastructure of the sporoderm morphogenesis in Psilotum nudum (L.) Griseb. Science Report of the Research Institute of Evolutionary Biology, 3, 171-181.

Uehara, K. \& Kurita, S. (1989). Ultrastructural Study of Spore Wall Morphogenesis in Ophioglossum thermale Kom. var. Nipponicum (Miyabe et Kudo) Nishida. The Botanical Magazine, Tokio, 102, 413-427.

Uehara, K. \& Kurita, S. (1991). Ultrastructural study on spore wall morphogenesis in Lycopodium clavatum (Lycopodiaceae). American Journal Botany, 78(1), 24-36.

Uehara, K., Kurita, S., Sahashi N., \& Ohmoto, T. (1991). Ultrastructural study of microspore wall morphogenesis in Isoetes japonica (Isoetaceae). American Journal of Botany, 78, 1182-1190.

Wallace, S., Fleming, A., Wellman, C. H., \& Beerling, D. J. (2011). Evolutionary development of the plant and spore wall. AoB PLANTS, 2011, 1-18.

Wagner, W. H. Jr. \& Beitel, J. M. (1992). Generic classification of modern North American Lycopodiaceae. Annals of the Missouri Botanical Garden, 79, 676-686.

Wagner, W. H. Jr. \& Beitel, J. M. (1993). Lycopodiaceae. In M. Windham (Ed.). Flora of North America 1 (pp.1837). NewYork, U.S.A: Oxford University Press.

Wellman, C. H. (2004). Origin, function and development of the spore wall in early land plants. In A. R. Hemsley \& I. Pole (Eds.), The evolution of plant physiology (pp. 43-63). Linnean Society Symposium, Number 21. San Diego, U.S.A.: Academic Press.

Wikström, N. (2001). Diversification and relationships of extant homosporous lycopods. American Journal Ferns, 91(3), 150-165.

Wikström, N. \& Kenrick, P. (1997). Phylogeny of Lycopodiaceae (Lycopsida) and the relationships of Phylloglossum drummondii Kunze based on rbcL sequences. International Journal of Plant Sciences, $58,862-871$.

Wikstrom, N. \& Kenrick, P. (2000a). Phylogeny of epiphytic Huperzia (Lycopodiaceae): paleotropical and neotropical clades corroborated by plastid $r b c L$ sequences. Nordic Journal of Botany, 20(2), 165-171.

Wikstrom, N. \& Kenrick, P. (2000 b). Relationships of Lycopodium and Lycopodiella based on combined plastid $r b c L$ gene and $\operatorname{trn} L$ intron sequence data. Systematic Botany, 25(3), 495-510.

Wikström, P. \& Kenrick, J. C. (2001). Evolution of Lycopodiaceae (Lycopsida): estimating divergence times from rbcL gene sequences by use of nonparametric rate smoothing. Molecular Phylogenetics and Evolution, 19(2), 177-186. 
Wikström, N., Kenrick, P., \& Chase, M. (1999). Epiphytism and terrestrialization in tropical Huperzia (Lycopodiaceae). Plant Systematics and Evolution, 218, 221-243.

Wilce, J. H. (1972). Lycopod spores, I. General spore patterns and the generic segregates of Lycopodium. American Fern Journal, 62(3), 365-79.
Willis, K. J. \& McElwain, J. E. (2002). The evolution of plants. $\left(I^{s t} e d\right.$.). New York, U.S.A: Oxford University Press.

Yatsentyuk, S. P., Valiejo-Roman, K. M., Samigullin, T. H., Wilkström, N., \& Troitsky, A. V. (2001). Evolution of Lycopodiaceae inferred from spacer sequencing of chloroplast rRNA genes. Russian Journal of Genetics, 37(9), 1274-1280. 


\section{APÉNDICE}

Origen de especímenes investigados

\section{Huperzia}

Huperzia arcuata B. Øllg. Colombia: Caldas: Municipio de Villa Maria, San Carlos, vía al Parque Nacional Natural los Nevados, 3377m, Rincón 004 (CUVC, HUA).

Huperzia attenuata (Spring) Trevis. Colombia: Cauca: entre los municipios de Puracé y Coconuco, $3404 \mathrm{~m}$, Rincón 010 (CUVC, HUA).

Huperzia brevifolia (Grev. \& Hook.) Holub. Colombia: Cauca: entre los municipios de Puracé y Coconuco, 3404m, Rincón 011 (CUVC, HUA).

Huperzia brongniartii (Spring) Trevis. Colombia: Choco: Municipio de San José del Palmar, cerro del Torrá, 2700-2880m, Silverstone-Sopkin et al. 4651 (CUVC).

Huperzia callitrichifolia (Mett.) Holub. Colombia: Cauca: Municipio de Almaguer, vereda La Riñonada, 2900 m, Ramirez P. \& Munar 17704 (CAUP).

Huperzia capellae (Herter) Holub. Colombia: Nariño: Municipio de Pasto, estribaciones cordillera CentroOriental, páramo Los Frailes. 3300-3350m, Ramírez P. 10918 (CAUP).

Huperzia crassa (Humb. \& Bonpl. Ex Willd.) Rothm. Colombia: Caldas: Municipio de Villa María, San Carlos, vía al Parque Nacional Natural los Nevados, 3377m, Rincón 012 (CUVC, HUA).

Huperzia curvifolia (Kunze) Holub. Colombia: Valle del Cauca: Municipio de Dagua, 1377m, SilverstoneSopkin 11359 (CUVC).

Huperzia dichaeoides (Maxon) Holub. Colombia: Cauca: Municipio de El Tambo, Reserva Natural Tambito, $1550 \mathrm{~m}$, Casañas Suarez 358 (CAUP).

Huperzia dichotoma (Jacq.) Trevis. Colombia: Valle del Cauca: Municipio de Calcedonia, Valle del rio La Vieja (Valle interior del lado occidental de la cordillera central), $1150 \mathrm{~m}$, Silverstone-Sopkin \& Paz 6983 (CUVC).

Huperzia ericifolia (C. Presl) Holub. Colombia: Cauca: Municipio de Popayán, Rio Molino, Vereda Santa Barbará, 1900m, Munar \& Ceballos 116 (CAUP).

Huperzia eversa (Poir.) B. Øllg. Colombia: Valle del Cauca: Municipio de Santiago de Cali, 1454m, Rincón 017 (CUVC, HUA).

Huperzia firma (Mett.) Holub. Colombia: Cauca: entre los municipios de Puracé y Coconuco, 3404m, Rincón 014 (CUVC, HUA).

Huperzia hartwegiana (Spring) Trevis. Colombia: Cauca: Municipio de Totoró, corregimiento El Hatico, finca Raíces de Vida, 2430m, Velasco 06 (CAUP).

Huperzia heteróclita (Desv. ex Poir.) Holub. Colombia: Cauca: Municipio de Coconuco, entre Puracé y el
Parque Nacional Natural, 3 180m, Medina et al. 03 (CAUP).

Huperzia hippuridea (Christ) Holub. Colombia: Cauca: Municipio de Totoró, finca Potrero del Rio, $3100 \mathrm{~m}$, Fernández 0.18 (CAUP)

Huperzia hohenackeri (Herter) Holub. Colombia: Caldas: Municipio de Villa María, San Carlos, vía al Parque Nacional Natural los Nevados, 3377m, Rincón 018 (CUVC, HUA).

Huperzia hystrix (Herter) Holub. Colombia: Choco: Municipio de San Jose del Palmar, Cerro del Torrá, 2700-2 800m, Silverstone-Sopkin 4652 (CUVC).

Huperzia kuesteri (Nessel) B. Øllg. Colombia: Cauca: Municipio de Silvia, vía Asnenga-Mosoco, cordillera central, Paramo de las Moras, 3000-3600m, Reina et al. 442 (CAUP).

Huperzia linifolia (L.) Trevis. Colombia: Cauca: Municipio de Cajibío, 1850m, Espinal T. \& Ramos 3169 (CUVC).

Huperzia molongensis (Herter) Holub. Colombia: Cauca: Municipio de Almaguer, Veredas Dominguillo y Guambial, camino a Guambial, 1800-3000m, Ramírez P. \& Munar 17682 (CAUP).

Huperzia phylicifolia (Desv. ex Poir.) Holub. Colombia: Cauca: entre los Municipios de Puracé y Coconuco, $3404 \mathrm{~m}$, Rincón 015 (CUVC, HUA).

Huperzia reflexa (Lam.) Trevis. Colombia: Valle del Cauca: Municipio de Santiago de Cali, 1454m, Rincón 013 (CUVC, HUA).

Huperzia rosenstockiana (Herter) Holub. Colombia: Caldas: Municipio de Villa María, San Carlos, vía al Parque Nacional Natural los Nevados, 3377m, Rincón 003 (CUVC, HUA).

Huperzia sarmentosa (Spring) Trevis. Colombia: Choco: Municipio de San Jose del Palmar, Cerro del Torrá, vertiente oriental, 2500m, Silverstone-Sopkin 4923 (CUVC).

Huperzia sellifolia B. Øllg. Colombia: Nariño: Municipio de Puerres, El Rosal, 3 300m, Ramírez P. 11861 (CAUP).

Huperzia subulata (Desv. ex Poir.) Holub. Colombia: Cauca: Municipio de Totoró, Paramo de San Pedro, $3000 \mathrm{~m}$, Espinal \& Ramos 3507 (CUVC).

Huperzia taxifolia (Sw.) Trevis. Colombia: Cauca: Municipio de Cajibío, 1850m, Espinal T. \& Ramos 3170 (CUVC).

Huperzia tenuis (Humb. \& Bonpl. ex Willd.) Trevis. Colombia: Nariño: Municipio de Ospina, páramo de Paja Blanca, alrededores de la bocatoma del acueducto, 3200m, Ramirez P. et al. 8909 (CAUP). 
Huperzia tetragona (Hook. \& Grev.) Trevis. Colombia: Cauca: entre los Municipios de Puracé y Coconuco, 3404m, Rincón 016 (CUVC, HUA).

Huperzia unguiculata B. Øllg. Colombia: Cauca: Municipio de Popayán, corregimiento de Quintana, laderas del cerro Toma Aire hasta el páramo, 3 200-3 660m, Sandoval et al 69 (CAUP).

\section{Lycopodiella s.l.}

Lycopodiella andicola B. Øllg. Colombia: Valle del Cauca: Municipio de Santiago de Cali, 1454m, Rincón 005 (CUVC, HUA).

Palhinhaea cernua (L.) Vasc. \& Franco. Colombia: Valle del Cauca: Municipio de Santiago de Cali, 1454m, Rincón 006 (CUVC, HUA).

Palhinhaea glaucescens (C. Presl) Holub. Colombia: Cauca: Municipio de Inza, vereda Rio Sucio, Jardín Botánico las Delicias, 2700-2800m, Muñoz et al. 2931 (CAUP).

Palhinhaea pendulina (Hook.) Holub. Colombia: Nariño: Municipio de Pasto, páramo El Frailejonal, a $8 \mathrm{Km}$ de Mocondino, 3400m, Ramirez P et al.10421 (CAUP).

Palhinhaea riofrioi (Sodiro) Holub. Colombia: Valle del Cauca: Municipio de El Cairo, vertiente oriental de la cordillera occidental, las Amarillas, Serranía de Los Paraguas, 2070-2125m, Silverstone-Sopkin et al. 3752 (CUVC).

Palhinhaea steyermarkii (B. Øllg.) Holub. Colombia: Choco: Municipio de San Jose del Palmar, Cerro del Torrá, 2730m, Silvertone-Sopkin et al. 4438 (CUVC).

Palhinhaea trianae (Hieron.) Holub. Colombia: Valle del Cauca: Municipio de Buenaventura, Bahía Málaga, Croat \& Gaskin 80462 (CUVC).

Pseudolycopodiella caroliniana (L.) Holub. Colombia: Cauca: Municipio de Popayán, vereda Real Palacé, cerca del rio Palacé, $1850 \mathrm{~m}$, Ramírez P. \& Macías P. 18226 (CAUP).

\section{Lycopodium s.l.}

Austrolycopodium magellanicum (P. Beauv.) Holub. Colombia: Cauca: Municipio de Popayán, corregimiento de Quintana, laderas del cerro Toma Aire hasta el páramo, $3200 \mathrm{~m}$, Sandoval et al. 62 (CAUP).

Diphasiastrum thyoides (Humb. \& Bonpl. ex Willd.) Holub. Colombia: Cauca: entre los municipios de Puracé y Coconuco, 3376m, Rincón 009 (CUVC, HUA).

Diphasium jussiaei (Desv. ex Poir.) Rothm. Colombia: Cauca: entre los municipios de Puracé y Coconuco, 3404m, Rincón 008 (CUVC, HUA).

Lycopodium clavatum subsp. clavatum L. Colombia: Cauca: entre los municipios de Puracé y Coconuco, 3404m, Rincón 007 (CUVC, HUA).

Lycopodium clavatum subsp. Contiguum (Klotzsch) B. Øllg. Colombia: Cauca: entre los municipios de Puracé y Coconuco, 3404m, Rincón 019 (CUVC, HUA). 
